Review Article

\title{
A SIGE-SINGEM-AIGO technical review on the clinical use of esophageal reflux monitoring
}

\author{
Edoardo Savarino ${ }^{\mathrm{a}, *}$, Marzio Frazzoni $^{\mathrm{b}}$, Elisa Marabotto ${ }^{\mathrm{c}}$, Patrizia Zentilin ${ }^{\mathrm{c}}$, Paola Iovino ${ }^{\mathrm{d}}$, \\ Mario Costantini ${ }^{\mathrm{e}}$, Salvatore Tolone ${ }^{\mathrm{f}}$, Edda Battagliag ${ }^{\mathrm{g}}$, Michele Cicala ${ }^{\mathrm{h}}$, Paolo Usai-Satta ${ }^{\mathrm{i}}$, \\ Nicola de Bortoli ${ }^{j}$, Roberto Penagini ${ }^{k, l}$, Vincenzo Savarino ${ }^{c}$ \\ ${ }^{a}$ Gastrointestinal Unit, Department of Surgery, Oncology and Gastroenterology, University of Padua, Padua, Italy \\ ${ }^{\mathrm{b}}$ Digestive Pathophysiology Unit, Baggiovara Hospital, Modena, Italy \\ ${ }^{\mathrm{c}}$ Gastrointestinal Unit, Department of Internal Medicine, University of Genoa, Genoa, Italy \\ ${ }^{\mathrm{d}}$ Gastroenterology Unit, University of Salerno, Salerno, Italy \\ e Clinica Chirurgica III, Department of Surgery, Oncology and Gastroenterology, University of Padua, Padua, Italy \\ ${ }^{\mathrm{f}}$ Surgery Unit, University of Campania Luigi Vanvitelli, Italy \\ ${ }^{g}$ Gastroenterology and Endoscopy Unit, Cardinal Massaja Hospital, Asti, Italy \\ ${ }^{\mathrm{h}}$ Unit of Digestive Diseases, Campus Bio Medico University, Rome, Italy

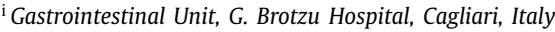 \\ ${ }^{\mathrm{j}}$ Gastrointestinal Unit-Department of Translational Sciences and New Technologies in Medicine and Surgery, University of Pisa, 56124 Pisa, Italy \\ ${ }^{\mathrm{k}}$ Gastroenterology and Endoscopy Unit - Department of Pathophysiology and Transplantation, Fondazione IRCCS Ca' Granda Ospedale Maggiore Policlinico - \\ University of Milan, Milan, Italy \\ ${ }^{1}$ Department of Pathophysiology and Transplantation, University of Milan, Italy
}

\section{A R T I C L E I N F O}

\section{Article history:}

Received 20 April 2020

Accepted 28 April 2020

Available online 6 June 2020

\section{Keywords:}

GERD

Manometry

Impedance

Reflux monitoring

Guidelines

\begin{abstract}
A B S T R A C T
Patients with esophageal symptoms potentially associated with gastroesophageal reflux disease such as heartburn, regurgitation, chest pain, or cough represent one of the most frequent reasons for referral to gastroenterological evaluation. The utility of esophageal reflux monitoring in clinical practice is: (1) to accurately define reflux burden, (2) to segregate patients according to reflux monitoring results as true GERD, reflux hypersensitivity and functional heartburn, and (3) to establish a treatment plan. With this in mind, in the last decade, investigations and technical advances, with the introduction of impedance-pH monitoring and wireless pH capsule, have enhanced our understanding and management of GERD. The following recommendations were discussed and approved after a comprehensive review of the medical literature pertaining to reflux testing techniques and their recent application. This review created under the auspices of the Società Italiana di Gastroenterologia ed Endoscopia Digestiva (SIGE), Società Italiana di Neuro-Gastro-Enterologia e Motilità (SINGEM) and Associazione Italiana Gastroenterologi ed Endoscopisti Digestivi Ospedalieri (AIGO) is intended to help clinicians in applying reflux studies in the most fruitful manner within the context of their patients with esophageal symptoms.
\end{abstract}

(C) 2020 Editrice Gastroenterologica Italiana S.r.l. Published by Elsevier Ltd. All rights reserved.

\section{Pathophysiology and diagnosis of GERD}

Pathophysiology. The most widely accepted definition of gastroesophageal reflux disease (GERD) is "a condition that develops when the reflux of stomach contents causes troublesome symptoms and/or complications" [1]. The pathophysiology of GERD is multifactorial and many mechanisms play a role in inducing the disease and its perception, including the impairment of esophago-gastric

\footnotetext{
th Guarantor of the article: Edoardo Savarino, $\mathrm{MD}, \mathrm{PhD}$.

* Corresponding author.

E-mail addresses: edoardo.savarino@unipd.it, esavarino@libero.it (E. Savarino).
}

junction (EGJ), reduced esophageal clearance, presence of transient lower esophageal sphincter relaxation (TLESR), altered mucosal permeability, differences in mucosal innervation and, lastly, hypersensitivity and hypervigilance [2-15].

The esophago-gastric junction (EGJ) consists of the lower esophageal sphincter (LES), the crural diaphragm (CD), and the anatomical flap valve, and acts as an anti-reflux barrier. LES is considered the intrinsic sphincter and is surrounded by oblique gastric fibers that are fastened to the striated muscle of $C D$ by the phreno-esophageal ligament, while the right crus of the diaphragm forms a sling that surrounds the distal esophagus (the extrinsic sphincter) augmenting the high-pressure zone of the LES $[16,17]$. 
A consistently low LES pressure has been described only in a small number of GERD patients [18], however, the recent application of high resolution manometry (HRM) has introduced new parameters that incorporate EGJ length and respiratory variability, such as the LES pressure integral (LES-PI) [19] or the EGJ contractile integral (EGJ-CI) [20,21], which have been demonstrated to be significantly decreased in GERD patients, although they need to be better standardized.

TLESR relaxation is a mechanism that allows gas venting from the stomach [22] and is recognized as the major determinant of gastroesophageal reflux (GER), but patients with GERD do not have more frequent TLESRs than controls. However, the quantity of acid reflux during TLESRs has been reported to be greater in GERD patients $[23,24]$.

A hiatal hernia $(\mathrm{HH})$ is present when a spatial dissociation of the anti-reflux barrier at the EGJ between the intrinsic sphincter and the extrinsic sphincter $C D$ exists, which is likely caused by the weakening or rupture of the phreno-esophageal ligament [25]. It has been accurately established that patients with HH have more reflux episodes and greater esophageal acid exposure than patients without HH [26]. When the LES lies constantly above the diaphragm, the swallow-associated re-reflux from the hiatal sac impairs esophageal clearance [27], allowing a prolonged acid exposure of the mucosa. In fact, patients with large HH show a severe alteration in the clearance of refluxate [28].

Ineffective esophageal motility (IEM) is a heterogeneous minor motility disorder diagnosed when $\geq 50 \%$ ineffective peristaltic sequences (distal contractile integral $<450 \mathrm{~mm} \mathrm{Hg} \mathrm{cm} \mathrm{s)} \mathrm{coexist}$ with normal LES relaxation on HRM. Severe IEM ( $>70 \%$ of ineffective sequences) is associated with greater quantity of refluxed material, but milder variants do not impact quality of life [6,2931]. Further, delayed gastric emptying and altered motor function of the proximal stomach have often been described in GERD, but it is uncertain how much these alterations contribute to increase GER [[32, 33].

The acid pocket was firstly described in 2001 as a layer of unbuffered acidic gastric juice that sits on top of the meal, close to the cardia, ready to reflux in the postprandial period [34]. The acid pocket is present in both GERD patients and controls. However, alterations in its location and/or distribution may favor acid reflux from the pocket and partially explain the difference between GERD patients and controls. It must be emphasized that the phenomenon of acid pocket is only present in postprandial periods and therefore does not explain reflux episodes occurring between meals and during nighttime.

Central obesity increases the intragastric pressure [35] and the gastroesophageal pressure gradient. Both of them favor the reflux of gastric content and are also predictors of HH development [36]. Thus, overweight has been reported as an important risk factor for both erosive esophagitis (EE) and non-erosive reflux disease (NERD) $[37,38]$.

In many cases the severity of esophageal acid exposure to gastric content does not directly correlate with the severity of symptoms, and one potential explanation is that mucosal afferent nerve fibers are deep and therefore distant from the lumen in patients with $\mathrm{EE}$ and $\mathrm{BE}$, who have the highest degrees of acid reflux [12]. In fact, patients with NERD, who have more superficial mucosal afferent nerves, and patients with proton pump inhibitors (PPIs) refractory symptoms are hypersensitive to minor stimuli, while patients with severe EE and Barrett esophagus are often hyposensitive or even asymptomatic [39-45]. In the last decade, a number of patient-related factors such as peripheral and central sensitization, impaired mucosal barrier function, behavior conditions like rumination syndrome, functional gastrointestinal disorders and possibly genetic factors together with reflux-related features (i.e., the acidity of the refluxate, the proximal extent of reflux episodes, and the presence of bile acids and gas in the refluxate), have been implicated to explain the differences in reflux perception among specific subtypes of GERD symptoms [46-56].

Diagnosis. In the suspect of GERD the diagnosis should begin with a thorough clinical history in order to recognize the typical symptoms, heartburn and regurgitation, and it is also necessary to characterize their intensity, frequency, duration, provoking and alleviating factors [[57-59]. Although their sensitivity and specificity are not ideal, typical symptoms are considered sufficient to make a presumptive diagnosis of GERD by taking into account the age and the absence of alarm features including dysphagia, odynophagia, progressive unintentional weight loss, GI tract bleeding, persistent pain, iron-deficiency anemia, frequent vomiting, family history of cancer and epigastric mass. If alarm symptoms occur, upper endoscopy must be considered. On the other hand, the absence of typical symptoms does not exclude the diagnosis of GERD, because also extra-esophageal manifestations, such as chronic cough, wheezing, hoarseness, globus, throat clearing/irritation should be taken into account [60-66].

The endoscopic finding of mucosal lesions (esophagitis, strictures, metaplasia and cancer) permits to achieve a certain diagnosis of GERD and this may occur also in patients with few symptoms or completely asymptomatic, although in the latter individuals the clinical value of these endoscopic findings is uncertain. However, it is well known that most patients (> 70\%) show no abnormalities on endoscopic examination.

An empirical trial of PPIs should be considered as part of the diagnostic workup for suspected GERD, always paying attention to the right indication and to stop the PPIs when not necessary [67-69]. Also, proper dosing and compliance must be assured, and, if only partial improvement is seen, some studies support using twice daily dosing or switching to another PPI before declaring the patient a "non-responder" [70,71]. Those who do not respond to a PPI trial or have extraesophageal symptoms should be evaluated for other diseases than GERD and only in presence of refractory or difficult cases, functional tests, such as ambulatory impedance-pH monitoring (MII-pH) and esophageal HRM, are indicated [72,73].

\section{Technical aspects of ambulatory $\mathrm{pH}$ monitoring}

\section{1. $\mathrm{PH}$, impedance- $\mathrm{pH}$ and wireless capsule techniques}

Introduced more than 40 years ago by Johnsson and DeMeester [74], intraluminal $\mathrm{pH}$ monitoring of the distal esophagus remains an important tool in the diagnosis of GERD. It was designed to quantitate the actual time the esophageal mucosa is exposed to acid.

However, in order to improve the assessment of other types of chemical refluxes, multichannel intraluminal impedance-pH (MII$\mathrm{pH}$ ) of the esophagus has been recently introduced. Impedance measures changes in resistance of a current passing through pairs of metal rings on a catheter. The integration of one or more $\mathrm{pH}$ sensors along the catheter adds the possibility of classifying these events as acid $(\mathrm{pH}<4)$, weakly acidic $(4>\mathrm{pH}<7)$ or weakly alkaline $(\mathrm{pH}>7)$. In other words, the test allows the detection of all type of refluxes, independently of their acidity. It is therefore considered the best tool to detect and characterize GER [75]. It is worth mentioning that there are some drawbacks also, especially the requirement of long and tedious visual analysis of the tracings, since available software is less dependable than that for the simpler $\mathrm{pH}$ analysis [76,77]. This is particularly true in case of severe esophagitis and Barrett's esophagus or severe impaired peristalsis, in which esophageal baseline impedance may be very low $[78,79]$.

Catheter-based studies have some limitations. Patients often report discomfort and restriction of usual activities which may alter results, $5-10 \%$ of them do not tolerate the catheter and in some 
Table 1

Clinical advantages and limitations of catheter-based and wireless pH-metry, multichannel intraluminal impedance-pH.

\begin{tabular}{|c|c|c|c|}
\hline Variables & MII-pH monitoring & $\begin{array}{l}\text { Catheter-based } \mathrm{pH} \\
\text { monitoring }\end{array}$ & Wireless pH monitoring \\
\hline 24-h Acid exposure time (AET) in distal and/or proximal esophagus & Yes $^{\&}$ & Yes & Yes \\
\hline 48-96- $h$ acid exposure time (AET) in distal and/or proximal esophagus & No & No & Yes \\
\hline Total (acid, weakly acidic and weakly alkaline) number of refluxes & Yes & No & No \\
\hline Total acid refluxes & Yes & Yes & Yes \\
\hline Total weakly acidic refluxes & Yes & No & No \\
\hline Total weakly alkaline refluxes & Yes & No & No \\
\hline $\begin{array}{l}\text { Gas movement } \\
\text { (gastric and supragastric belching) }\end{array}$ & Yes & No & No \\
\hline $\begin{array}{l}\text { Bolus movement (distinction between reflux and swallows, identification of meals and } \\
\text { artifacts, rumination) }\end{array}$ & Yes & No & No \\
\hline Proximal migration of reflux episodes & Yes & No & No \\
\hline Post-prandial reflux monioring & Yes & Limited $^{f}$ & Limited ${ }^{£}$ \\
\hline Monitoring Off-PPI evaluation & Yes & Yes & Yes \\
\hline Monitoring On-PPI evaluation & Yes & Limited $^{£}$ & Limited $^{£}$ \\
\hline Mucosal Integrity (Mean Nocturnal Baseline Impedance) & Yes & No & No \\
\hline Acid clearance & Yes & Yes & Yes \\
\hline Bolus Clearance & Yes & No & No \\
\hline Chemical clearance (Post-reflux Swallow-induced Peristaltic Wave index) & Yes & No & No \\
\hline $\begin{array}{l}\text { Symptom-reflux Association (Symptom Index (SI) and Symptom Association Probability } \\
\text { (SAP) measured for acid, weakly acidic and weakly alkaline reflux episodes) }\end{array}$ & Yes & Limited $^{£}$ & Limited $^{£, *}$ \\
\hline Distinction between GERD, reflux hypersensitivity and functional heartburn & Yes & Limited $^{£}$ & Limited $^{£}$ \\
\hline Tolerability & Moderate & Moderate & Good \\
\hline Cost & Medium & Low & High \\
\hline
\end{tabular}

\& it can also be corrected by excluding false positive $\mathrm{pH}$ drops according to impedance.

${ }^{£}$ Limited by acid assessment only.

* Increased probability of symptoms reporting and association due to prolonged recording.

of the patients symptom reflux association cannot be assessed because they do not refer any of their clinically relevant symptoms during the 24 h [57]. Furthermore, esophageal acid exposure has day-to-day variability which may impair accuracy of $24 \mathrm{~h}$ studies in diagnosing GERD, especially in endoscopy negative patients [57]. In order to overcome these limitations, a wireless system, consisting in a $\mathrm{pH}$-sensitive capsule clipped to the esophageal mucosa and transmitting data to an external data-logger, has been introduced [80]. It allows for recording during a prolonged period of time, beyond the traditional limit of the $24 \mathrm{~h}$ (48-96 h). The test, which often uses endoscopy in order to place the capsule, is however far more expensive than catheter-based studies and should be reserved for selected patients (see "Clinical indications"). Moreover, the usefulness of the test is limited to the detection of acid refluxes only.

Clinical advantages and limitations of catheter-based and wireless pH-metry, multichannel intraluminal impedance-pH are illustrated in Table 1.

\subsection{Data-loggers}

$\mathrm{pH}$ data from the distal esophagus are usually stored into lightweight, battery-powered data-loggers, that should sample the esophageal $\mathrm{pH}$ at $4-6 \mathrm{~s}$ intervals $(0.25-0.17 \mathrm{~Hz})$, over 1 to $3 \mathrm{pH}$ channels, for a conventional 24-h period, even if some data suggest that shorter periods (e.g.: $16 \mathrm{~h}$ ) may provide accurate information and improve patients' tolerance [81]. Even if a 4-6s sampling frequency may miss intra-esophageal pH decreases below 4.0 units lasting for a few seconds, this is not relevant for the clinical value of the study, whereas a lower sampling rate $(<8 \mathrm{~s}$ or $0.125 \mathrm{~Hz})$ is certainly inaccurate [82].

Data-loggers for MII-pH studies are similar to those for traditional pH-monitoring, with the additional capacity of recording multiple (usually 6-8) impedance channels at $50 \mathrm{~Hz}$ sampling frequency [75].

At the end of the test, the raw data are uploaded in a computer (via a USB, proprietary or wireless connection) for the analysis and storage. Various, proprietary soft-wares are available for analysis of the data acquired with the different systems commercially available.

\subsection{Electrodes}

Several types of $\mathrm{pH}$ electrodes are available [83,84]: A) Bi-polar glass electrodes (with internal reference) are the most accurate, and allow for multiple recording cycles (50 and more) if carefully handled, but they are restricted to a single sensor; B) Antimony monocrystalline electrodes are inferior to glass electrodes for $\mathrm{pH}$ sensitivity, response rate, temperature sensitivity and time-related drifts, but they are cheaper and smaller, and allow for multiple sensors to be assembled in a single catheter, making them the most suitable for routinary clinical use. They may be re-usable for a very limited number of tests (3-5), but the rapid deterioration in their function makes the use of the disposable ones preferable; C) Ion-sensitive field effect (ISFET) electrodes have also been introduced in the clinical use [85]. They seem to combine the accuracy and sensitivity of glass electrodes with the size of the antimony ones. However, at present, they are very costly and so used only in few centers.

Impedance-pH catheters may be assembled in different ways. Normally, they have a $\mathrm{pH}$ electrode to be placed in the distal esophagus, $5 \mathrm{~cm}$ from the LES, and several (6 to 8) pairs of impedance sensors (each composed of two metal rings) usually spaced $2-\mathrm{cm}$ apart, assembled to measure impedance changes along the esophagus, at 3, 5, 7, 9, 15 and $17 \mathrm{~cm}$ proximal to LES. Additional $\mathrm{pH}$ sensors may be located distally or proximally, for recording the stomach or proximal esophagus $\mathrm{pH}$ changes, and the impedance sensors may be differently assembled (Fig. 1). There are no available studies comparing different configurations of the probes, but a catheter with 6 impedance segments and at least $1 \mathrm{pH}$ electrode should allow for a correct detection of reflux [86].

The wireless $\mathrm{pH}$ sensor consists of a pH-sensing $25 \mathrm{~mm}$-long capsule that is attached to the esophageal mucosa. It has an antimony $\mathrm{pH}$ and a reference electrode located at the distal tip. An internal battery allows the instant transmission of the detected $\mathrm{pH}$ 


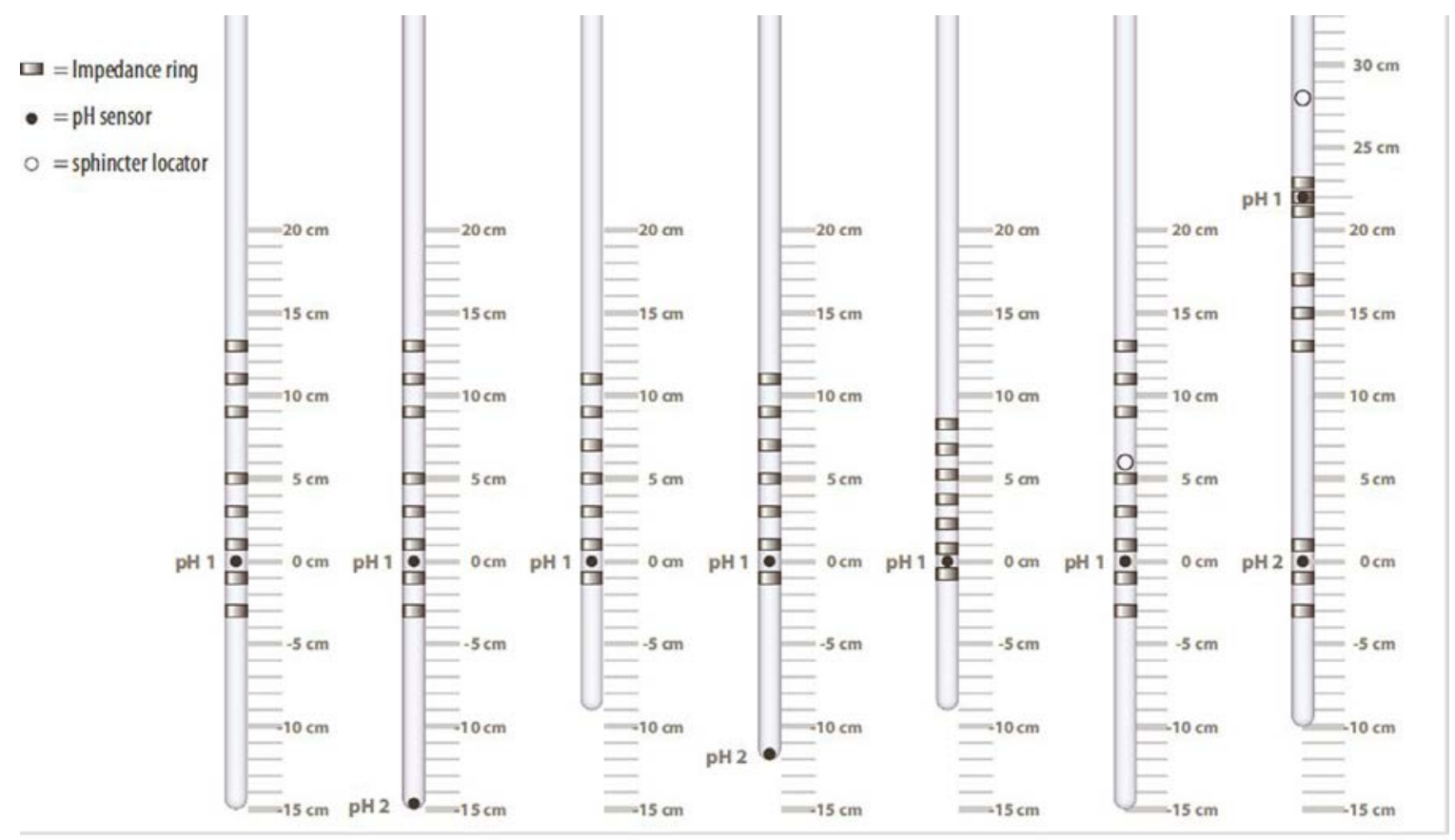

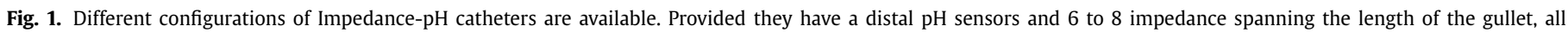
the represented configurations can be used for a correct study.

data via a radiofrequency signal $(433 \mathrm{MHz})$ to the external receiver [80].

\subsection{Electrode and wireless capsule placement}

This point is crucial for a correct and dependable test. By convention, the $\mathrm{pH}$ sensor is usually placed $5 \mathrm{~cm}$ above the upper border of the LES, manometrically detected. This position, suggested when the test was first introduced [74], aims to avoid the sensor to fall below, in the proximal stomach, during esophageal shortening with swallows, or the under-estimation of reflux episodes if placed too high in the esophagus [87]. Manometry before the $\mathrm{pH}$-test (be it conventional or high-resolution), is strongly encouraged, besides the useful additional information it may provide on esophageal motility and LES competence. Other methods with radiographic or endoscopic localization techniques have long been abandoned for their inaccuracy [88]. The pH "step-up" technique (putting the probe into the stomach with a detectable acidic $\mathrm{pH}$, and then slowly withdrawing it until a change in $\mathrm{pH}$ occurs, and then withdrawing it for $5 \mathrm{~cm}$ more) has resulted to be inaccurate, especially in case of hiatus hernia [89].

Impedance-pH catheters are usually placed in the same fashion, with the distal esophageal $\mathrm{pH}$ sensor located $5 \mathrm{~cm}$ above the upper border of the LES, which represents the key-point for a correct test evaluating acid gastro-esophageal reflux [86]. The impedance rings will then span the entire length of the gullet, and the additional $\mathrm{pH}$ sensors will monitor the proximal esophageal and/or gastric $\mathrm{pH}$, depending on the configuration of the catheter. Recently an impedance step-up method has been described whereby the $\mathrm{pH}$ sensor is placed $6 \mathrm{~cm}$ above the sharp increase in impedance [90].

As far as the placement of the wireless pH-capsule is concerned, the trans-nasal positioning after the LES has been located with a trans-nasal manometry, is theoretically the most accurate method. However, the capsule introducer is bulky, little comfortable for the patient's nose, resulting in a failure rate to intubate in up to $20 \%$, with up to $13 \%$ adverse events, namely nose bleeding [80]. Transoral positioning with endoscopic guidance $6 \mathrm{~cm}$ above the Z-line [80] or $9 \mathrm{~cm}$ above the upper border of the manometrically detected LES (with a calculated correction factor of about $4 \mathrm{~cm}$ for the difference between the naso- and oro-esophageal route) [91], have both been validated and are generally used.

\subsection{Mucosal impedance}

The use of direct, rapid, endoscopic-guided, measurements of mucosal impedance (MI) has been recently proposed for diagnosing chronic GERD [92]. There are some evidences that patients with GERD have lower MI values compared with non-GERD patients [93]. Despite simplicity and availability of immediate results, MI is not able to determine degree, type, extent and different patterns of reflux. More research is needed to further determine its exact role.

\subsection{Pharyngeal pH-monitoring}

A 24-h monitoring of oropharyngeal $\mathrm{pH}$ using the Restech system (Respiratory Technology Corporation) has been recently proposed to detect supra-esophageal GERD [94]. Simultaneous measurements of combined $\mathrm{pH} / \mathrm{MII}$ and pharyngeal-pH have, however, showed poor correlation in many cases [95]. Pharyngeal $\mathrm{pH}$ monitoring could better predict a successful outcome for extraesophageal reflux symptoms after anti-reflux surgery [96]. In any case the diagnostic role of this technique remains unclear and its use can only be recommended for patients in the research study setting.

\subsection{Scoring variables (AET, DeMeester score, number of refluxes, PSPW index and impedance baseline)}

Whilst conventional esophageal $\mathrm{pH}$ monitoring provides a marker that acid is present in the esophagus and expresses this as a function of time, impedance monitoring can detect physical liquid and gas movements into the esophagus. Thus, several variables can be assessed during reflux monitoring (Table 2). 
Table 2

Variables assessed during ambulatory reflux monitoring using catheter-based and wireless pH-metry, multichannel intraluminal impedance-pH, mucosal impedance and bilitec.

\begin{tabular}{|c|c|c|c|c|c|c|c|c|c|c|}
\hline Variables & Information & $\begin{array}{l}\text { Normal } \\
\text { Values }^{\&}\end{array}$ & CB-pH & MII-pH & W-pH & MIT & Bil & $\begin{array}{l}\text { Manual/Automated } \\
\text { calculation }\end{array}$ & $\begin{array}{l}\text { Associated to } \\
\text { Medical Outcome }\end{array}$ & $\begin{array}{l}\text { Associated to } \\
\text { Surgical Outcome }\end{array}$ \\
\hline $\begin{array}{l}\text { Acid Exposure } \\
\text { Time (AET;\%) }\end{array}$ & $\begin{array}{l}\text { Total time (\%) with esophageal } \mathrm{pH}<4.0 \text { units divided } \\
\text { by the time monitored }\end{array}$ & $\begin{array}{l}<4.0 \%[57] \\
\text { See Table } 3\end{array}$ & $\mathrm{x}$ & $\mathrm{x}$ & $\mathrm{x}$ & - & - & Auto & Yes & Yes \\
\hline $\begin{array}{l}\text { AET } \\
\text { Upright/Recumbent } \\
(\%)\end{array}$ & $\begin{array}{l}\text { Total time (\%) with esophageal } \mathrm{pH}<4 \text { during } \\
\text { pre-defined upright/recumbent positions }\end{array}$ & - & $\mathrm{x}$ & $\mathrm{x}$ & $\mathrm{x}$ & - & - & Auto & No & No \\
\hline $\begin{array}{l}\text { Acid reflux events } \\
\text { (according to pH } \\
\text { only; No.) }\end{array}$ & Number of events with esophageal $\mathrm{pH}<4.0$ units & - & $\mathrm{x}$ & $\mathrm{x}$ & $\mathrm{x}$ & - & - & Auto & No & No \\
\hline $\begin{array}{l}\text { Refluxes longer } \\
\text { than } 5 \text { min (No.) }\end{array}$ & $\begin{array}{l}\text { Number of acid reflux with acid exposure longer than } \\
5 \text { min }\end{array}$ & - & $\mathrm{x}$ & $\mathrm{x}$ & $\mathrm{x}$ & - & - & Auto & No & No \\
\hline $\begin{array}{l}\text { Longest reflux } \\
\text { episode }\end{array}$ & Acid reflux with the longest duration $/ 24 \mathrm{~h}$ & - & $\mathrm{x}$ & $\mathrm{x}$ & $\mathrm{x}$ & - & - & Auto & No & No \\
\hline $\begin{array}{l}\text { De Meester Score } \\
\text { (DMS) }\end{array}$ & $\begin{array}{l}\text { Composite score of acid exposure during } 24-\mathrm{h} \\
\text { ambulatory pH monitoring }\end{array}$ & $<14.7[74]$ & $\mathrm{x}$ & $\mathrm{x}$ & $\mathrm{x}$ & - & - & Auto & Yes & Yes \\
\hline $\begin{array}{l}\text { Mean Acid } \\
\text { Clearance Time } \\
\text { (MACT; seconds) }\end{array}$ & $\begin{array}{l}\text { Measure of esophageal acid clearance capacity } \\
\text { expressed as mean time in seconds required for the } \\
\text { pH to increase over } 4 \text { after an acidic reflux }\end{array}$ & - & $\mathrm{x}$ & $\mathrm{x}$ & $\mathrm{x}$ & - & - & Auto & No & No \\
\hline $\begin{array}{l}\text { Total number of } \\
\text { reflux events (No.) }\end{array}$ & $\begin{array}{l}\text { Total number of retrograde liquid (or mixed) reflux } \\
\text { events }\end{array}$ & $\begin{array}{l}<40[57] \\
\text { See Table } 3\end{array}$ & - & $\mathrm{x}$ & - & - & - & Manual & No & No \\
\hline $\begin{array}{l}\text { Acid reflux events } \\
\text { (No.) }\end{array}$ & $\begin{array}{l}\text { Retrograde liquid movements with esophageal } \mathrm{pH}< \\
4.0 \text { units }\end{array}$ & - & - & $\mathrm{x}$ & - & - & - & Manual & No & No \\
\hline $\begin{array}{l}\text { Weakly acidic } \\
\text { events (No.) }\end{array}$ & $\begin{array}{l}\text { Retrograde liquid movements with esophageal } \mathrm{pH}> \\
4.0 \text { and } \mathrm{pH}<7.0 \text { units }\end{array}$ & - & - & $\mathrm{x}$ & - & - & - & Manual & No & No \\
\hline $\begin{array}{l}\text { Weakly alkaline } \\
\text { events (No.) }\end{array}$ & $\begin{array}{l}\text { Retrograde liquid movements with esophageal } \mathrm{pH}> \\
7.0 \text { units }\end{array}$ & - & - & $\mathrm{x}$ & - & - & - & Manual & No & No \\
\hline $\begin{array}{l}\text { Median Bolus } \\
\text { Clearance Time } \\
\text { (MBCT, seconds) }\end{array}$ & $\begin{array}{l}\text { Measure of esophageal bolus clearance capacity } \\
\text { expressed as mean time in seconds from the initial } \\
\text { drop in impedance, when the liquid bolus enters the } \\
\text { impedance-measuring segment located at } 5 \mathrm{~cm} \text { above } \\
\text { the LES, to the rise in impedance as the bolus is } \\
\text { cleared from this segment by a peristaltic wave, thus } \\
\text { returning to baseline }\end{array}$ & - & - & $\mathrm{x}$ & - & - & - & Auto & No & No \\
\hline
\end{tabular}




\section{Table 2 (continued)}

\begin{tabular}{|c|c|c|c|c|c|c|c|c|c|c|}
\hline Variables & Information & $\begin{array}{l}\text { Normal } \\
\text { Values }^{\&}\end{array}$ & CB-pH & MII-pH & W-pH & MIT & Bil & $\begin{array}{l}\text { Manual/Automated } \\
\text { calculation }\end{array}$ & $\begin{array}{l}\text { Associated to } \\
\text { Medical Outcome }\end{array}$ & $\begin{array}{l}\text { Associated to } \\
\text { Surgical Outcome }\end{array}$ \\
\hline $\begin{array}{l}\text { Reflux exposure } \\
\text { time (RET,\%) }\end{array}$ & $\begin{array}{l}\text { Analogous to esophageal acid exposure plus the } \\
\text { duration of all four reflux subcategories (acid, weakly } \\
\text { acidic, weakly alkaline and superimposed reflux) } \\
\text { defined by impedance and dividing this value by } \\
\text { the time monitored }\end{array}$ & $\begin{array}{l}<1.4 \% \\
\text { [117] See } \\
\text { Table } 3\end{array}$ & - & $\mathrm{x}$ & - & - & - & Auto & No & No \\
\hline $\begin{array}{l}\text { Symptom Index } \\
(\mathrm{SI}, \%)\end{array}$ & $\begin{array}{l}\text { Parameter to calculate symptom-reflux association } \\
\text { (number of acid-related symptoms / total number } \\
\text { of symptoms) x } 100 \%\end{array}$ & $\begin{array}{l}<50 \% \\
{[124]}\end{array}$ & $\mathrm{x}$ & $\mathrm{x}$ & $\mathrm{x}$ & - & - & Auto/Manual & Yes $^{\#, \S}$ & Yes \\
\hline $\begin{array}{l}\text { Symptom } \\
\text { Association } \\
\text { Probability (SAP,\%) }\end{array}$ & $\begin{array}{l}\text { Parameter to calculate symptom-reflux association, } \\
\text { based on statistical analysis (cross tabulation) of a } \\
\text { contingency table consisting of four possible } \\
\text { combinations of reflux and symptoms. }\end{array}$ & $\begin{array}{l}<95 \% \\
{[126]}\end{array}$ & $\mathrm{x}$ & $\mathrm{x}$ & $\mathrm{x}$ & - & - & Auto & Yes \#,§ & Yes \\
\hline $\begin{array}{l}\text { Mean Nocturnal } \\
\text { Baseline } \\
\text { Impedance (MNBI) }\end{array}$ & $\begin{array}{l}\text { Mucosal integrity measured from the most distal } \\
\text { impedance channel during nighttime recumbent } \\
\text { period. The manually calculated mean of three } \\
10-\text {-minute time periods (around } 1.00 \mathrm{am}, 2.00 \mathrm{am} \text {, } \\
\text { and } 3.00 \mathrm{am} \text { ) is used with the software computing } \\
\text { the mean baseline for each period. }\end{array}$ & $\begin{array}{l}>2292 \\
\text { Ohms } \\
{[101]}\end{array}$ & - & $\mathrm{x}$ & - & - & - & Manual & Yes & Yes \\
\hline $\begin{array}{l}\text { Post-Reflux } \\
\text { Swallowed-induced } \\
\text { Peristaltic Wave } \\
\text { (PSPW) index }\end{array}$ & $\begin{array}{l}\text { Expression of chemical clearance and defined as an } \\
\text { antegrade } 50 \% \text { drop in impedance relative to the } \\
\text { pre-swallow baseline originating in the proximal } \\
\text { impedance sites, reaching the distal impedance sites, } \\
\text { and followed by at least } 50 \% \text { return to the baseline in } \\
\text { the distal impedance sites }\end{array}$ & $\begin{array}{l}>61 \% \\
{[101]}\end{array}$ & - & $\mathrm{x}$ & - & - & - & Manual & Yes & Yes \\
\hline Biliary reflux & $\begin{array}{l}\text { Esophageal biliary exposure defined as an increase in } \\
\text { bilirubin absorbance level } \geq 0.14 \text { for at least } 10 \mathrm{~s} \text {. }\end{array}$ & $\begin{array}{l}<1.8 \% \\
{[167]}\end{array}$ & - & - & - & - & $\mathrm{x}$ & Auto & No & No \\
\hline $\begin{array}{l}\text { Mucosal } \\
\text { impedance test } \\
\text { (MIT) }\end{array}$ & $\begin{array}{l}\text { Mucosal integrity measured with a balloon mucosal } \\
\text { impedance catheter system in esophageal mucosal } \\
\text { integrity during endoscopy over a long segment of } \\
\text { the esophagus }\end{array}$ & $\begin{array}{l}<2300 \\
\text { Ohms } \\
{[168]}\end{array}$ & - & - & - & $\mathrm{x}$ & - & Auto & No & No \\
\hline
\end{tabular}

LEGEND:

$\mathrm{CB}-\mathrm{pH}=$ catheter-based $\mathrm{pH} ; \mathrm{MII}-\mathrm{pH}=$ multichannel intraluminal impedance- $\mathrm{pH} ; \mathrm{W}-\mathrm{pH}=$ wireless $\mathrm{pH}$; $\mathrm{MIT}=$ mucosal impedance test; Bil=Bilitec.

\& Normal values more commonly used in clinical practice for diagnosing the different phenotypes of GERD.

\# At least 3 events per typical symptom must be reported for calculation of symptom-reflux association.

$\S$ Both SAP and SI positive represent stronger symptom-reflux association compared to either alone. If SAP and SI are both positive, the probability of PPI response is greater than when both indices are negative. 
The most frequently used and reproducible parameter to quantify esophageal acid exposure time (AET) is the percentage of time during which the $\mathrm{pH}<4.0$ units [97]. Classical reasons for choosing this cut-off $(\mathrm{pH}<4.0)$ value include observations that pepsin, the main proteolytic enzyme of the gastric secretions, is inactive above 4.0 units and the fact that GERD patients are more likely to report heartburn at an intra-esophageal pH below 4.0 units [98]. A cumulative score, the DeMeester score, represents another variable useful to estimate esophageal acid exposure, being able to discriminate between healthy volunteers and GERD patients [74]. This score is automatically calculated and reported by most commercially available $\mathrm{pH}$ software programs along with individual exposure times. Moreover, the calculation of the score showed to overcome some sex- and age-related variability in the simple AET, albeit small. A major weakness of the score is that it does not include any information on symptom/reflux association.

Multiple intraluminal impedance-pH (MII-pH) monitoring is capable of differentiating the antegrade and retrograde bolus transit of both liquid and gas, but is not able to detect either the acid content or volume of the intraluminal contents. In addition, impedance-pH can differentiate swallowed acidic foods from true reflux [99]. Swallows are detected as impedance changes progress from proximal to distal parts of the esophagus indicating an aboral bolus movement, which is the opposite of the reflux coming from the stomach (retrograde movement). Physical definition of reflux at impedance: a retrograde $50 \%$ fall in impedance from the baseline in the two distal impedance sites indicates the presence of liquid-only reflux. Gas-only reflux is defined as an increase in impedance $>3000 \Omega$ in any two consecutive impedance rings with one site having an absolute value $>7000 \Omega$. When a fall in impedance to $<50 \%$ of resting impedance (liquid) is preceded or followed by an abrupt rise in impedance (gas), it is defined to be a mixed refluxate. A pH electrode is typically incorporated into the recording assembly [97]. The chemical characteristics of the refluxate are defined in accordance with the criteria proposed by the Porto classification [75]. Changes in $\mathrm{pH}$ measurements occurring simultaneously with at least $50 \%$ falls in impedance are classified as follows: (a) acid reflux: a $\mathrm{pH}$ fall to $<4.0$ from a pre-event $\mathrm{pH}$ $>4.0$ units lasting for $>5 \mathrm{~s}$; (b) superimposed acid reflux: liquid reflux monitored by impedance electrodes while esophageal $\mathrm{pH}$ is still $<4.0$ units, i.e., $\mathrm{pH}$ in the distal esophagus has not returned to $>4.0$ units after an acid reflux; (c) weakly acidic reflux: $\mathrm{pH}$ nadir is $\geq 4.0$ but $<7.0$ units during reflux; (d) weakly alkaline reflux: no acid is present as intra-esophageal $\mathrm{pH}$ increases to $\geq 7.0$ or remains $\geq 7.0$ units during reflux. Extent of reflux migration is usually calculated for the liquid component in both liquid-only and mixed gas-liquid reflux events. Distal reflux is considered when confined to $5 \mathrm{~cm}$ above the LES, while reflux is defined proximal if it has reached $15 \mathrm{~cm}$ above the LES.

Based on these concepts, MII-pH allows to detect not only AET, but also number and period of occurrence of reflux episodes (upright, recumbent, total, and during post prandial period), as well as their physical (gas, liquid and mixed reflux) and chemical (acid, weakly acidic and weakly alkaline reflux) characteristics. Finally, investigators can also determine the number of reflux events reaching the most cranial impedance segment (proximal extent).

During impedance monitoring, it can be possible to assess the property of clearance of the esophagus (median bolus clearing time, expressed in upright, recumbent and total time in s), evaluating the presence in $s$ of the refluxate in the impedance channel conventionally located $5 \mathrm{~cm}$ above the LES [100]. Bolus exposure time is defined as the time from liquid bolus entry (50\% fall in impedance from the baseline) to liquid bolus clearance (impedance increase to the value denoting liquid reflux entry for $\geq 5 \mathrm{~s}$ ). Measurement of esophageal bolus clearance time has been found to reflect reflux severity, confirming the pathophysiological relevance of esophageal clearance in reflux disease and could be of help in confirming GERD diagnosis, but manual calculation is required [100].

Recently, two novel impedance parameters evaluating esophageal chemical clearance and mucosal integrity, namely the post-reflux swallow-induced peristaltic wave (PSPW) index and the mean nocturnal baseline impedance (MNBI) have been proposed [101]. Both indexes have already accumulated an important body of medical literature supporting their use in clinical practice, particularly for the MNBI, and various expert consensus reports and guidelines have suggested their adoption.

A PSPW (Fig. 2) is defined as an antegrade 50\% drop in impedance relative to the pre-swallow baseline originating in the most proximal impedance sites, reaching the distal impedance sites, and followed by at least $50 \%$ return to the baseline in the distal impedance sites (bolus exit) [101]. Post-reflux swallows that do not reach the distal impedance sites or occurring more than $30 \mathrm{~s}$ after the end of reflux episodes are not taken into account. For each impedance-pH tracing, the investigator should divide the number of refluxes followed within $30 \mathrm{~s}$ by a PSPW by the number of total refluxes (manual calculation) in order to obtain the PSPW index. The PSPW index reflects the integrity of esophageal peristalsis stimulated by reflux episodes and is expression of the chemical clearance due to saliva containing a large amount of bicarbonate [101]. It has been shown that a defective chemical clearance is associated with reflux esophagitis and with impaired mucosal integrity in NERD, as evaluated by MNBI [101]. In addition, the diagnostic yield of impedance-pH monitoring is increased by calculating both PSPW and MNBI off- as well as on-PPI therapy [102,103]: actually, these two parameters efficiently distinguish NERD and reflux hypersensitivity (RH) from FH and can be useful in selecting candidates for anti-reflux surgery [103]. Finally, it has been demonstrated that lack of improvement of impaired chemical clearance characterizes PPI-refractory reflux-related heartburn [104] as well as patients with eosinophilic esophagitis not responding to PPI therapy [105].

MNBI (Fig. 3) is assessed from the most distal impedance channel during nighttime recumbent period. Three 10 -min time periods (around $1.00 \mathrm{am}, 2.00 \mathrm{am}$, and $3.00 \mathrm{am}$ ) are selected and the software computes the mean baseline for each period. Time periods including swallows, refluxes and $\mathrm{pH}$ drops must be avoided. The mean of the three measurements is then manually calculated to obtain the MNBI. The MNBI is expression of mucosal integrity and provides evidence of esophageal macroscopic and microscopic damage after reflux exposure, therefore low values of this parameter have been found in patients with both erosive and non-erosive GERD, while normal MNBI levels are present in patients with FH $[102,103]$. In addition, low MNBI levels are associated with PPI response in patients with normal conventional impedance-pH parameters [106] and predict PPI response better than AET [107]; moreover, low MNBI values are predictive of positive response to medical as well as to surgical treatment [108].

Among impedance metrics, according to a recent consensus, number of reflux episodes (acidic, weakly acidic or weakly alkaline) should be considered normal when less than 40/24 h and abnormal over $80 / 24 \mathrm{~h}$ [57]. Intermediate values of both number of reflux episodes are inconclusive for GERD diagnosis, if considered alone. An abnormal number of reflux episodes is a useful metric mostly in borderline AET, even though is not enough on its own to predict response to medical therapy and to indicate anti-reflux surgery.

\subsection{Dietary and/or activity limitations}

Patients are usually asked to fast for at least $4 \mathrm{~h}$ prior to placing the $\mathrm{pH} /$ impedance-pH probe. During the monitoring period patients are instructed to reproduce as much as possible 


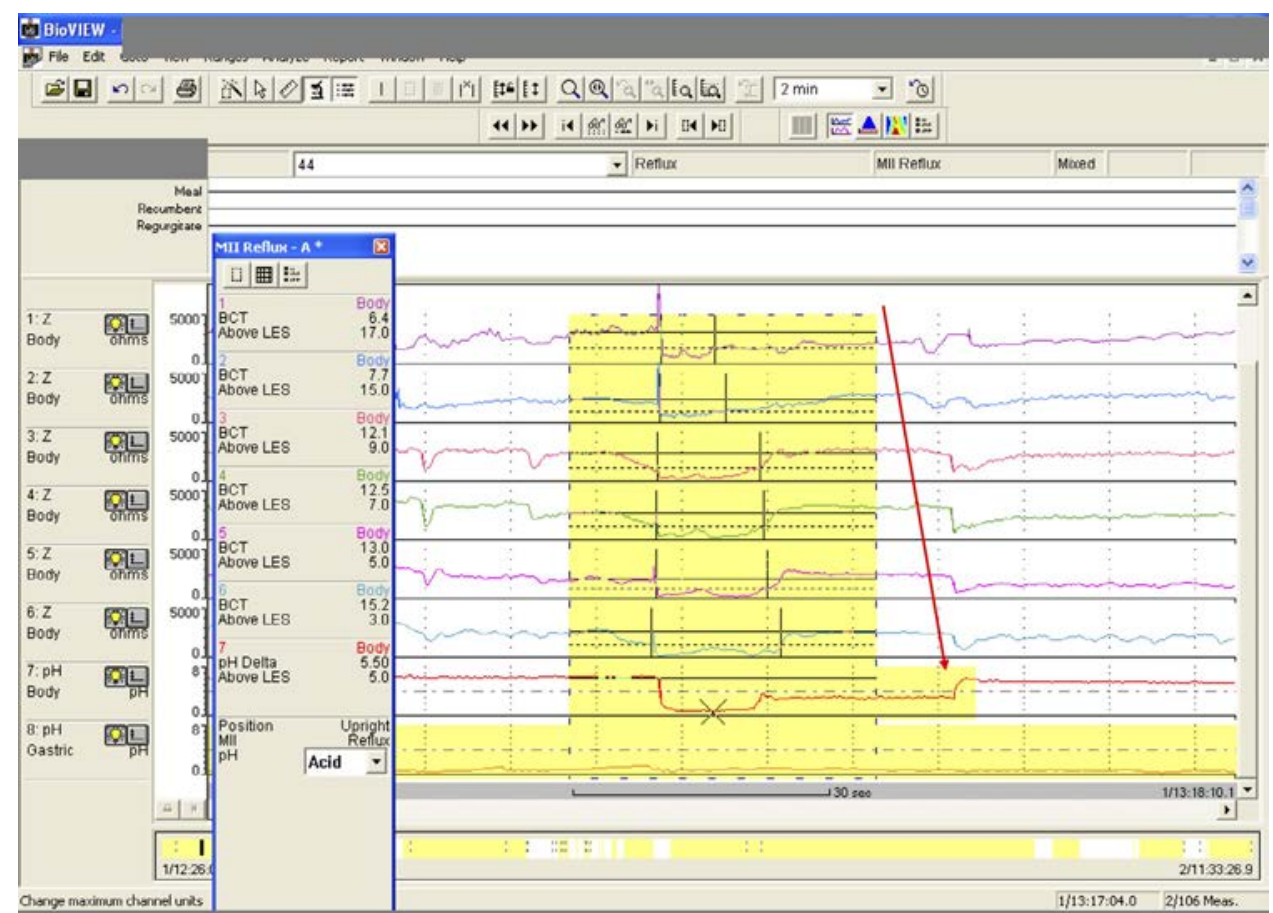

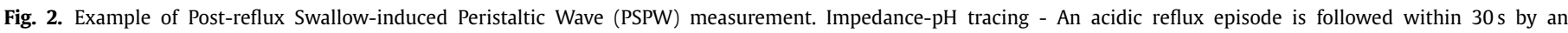
impedance drop from the proximal to the distal esophagus (red arrow), which represents a post-reflux swallow-induced peristaltic wave (PSPW).

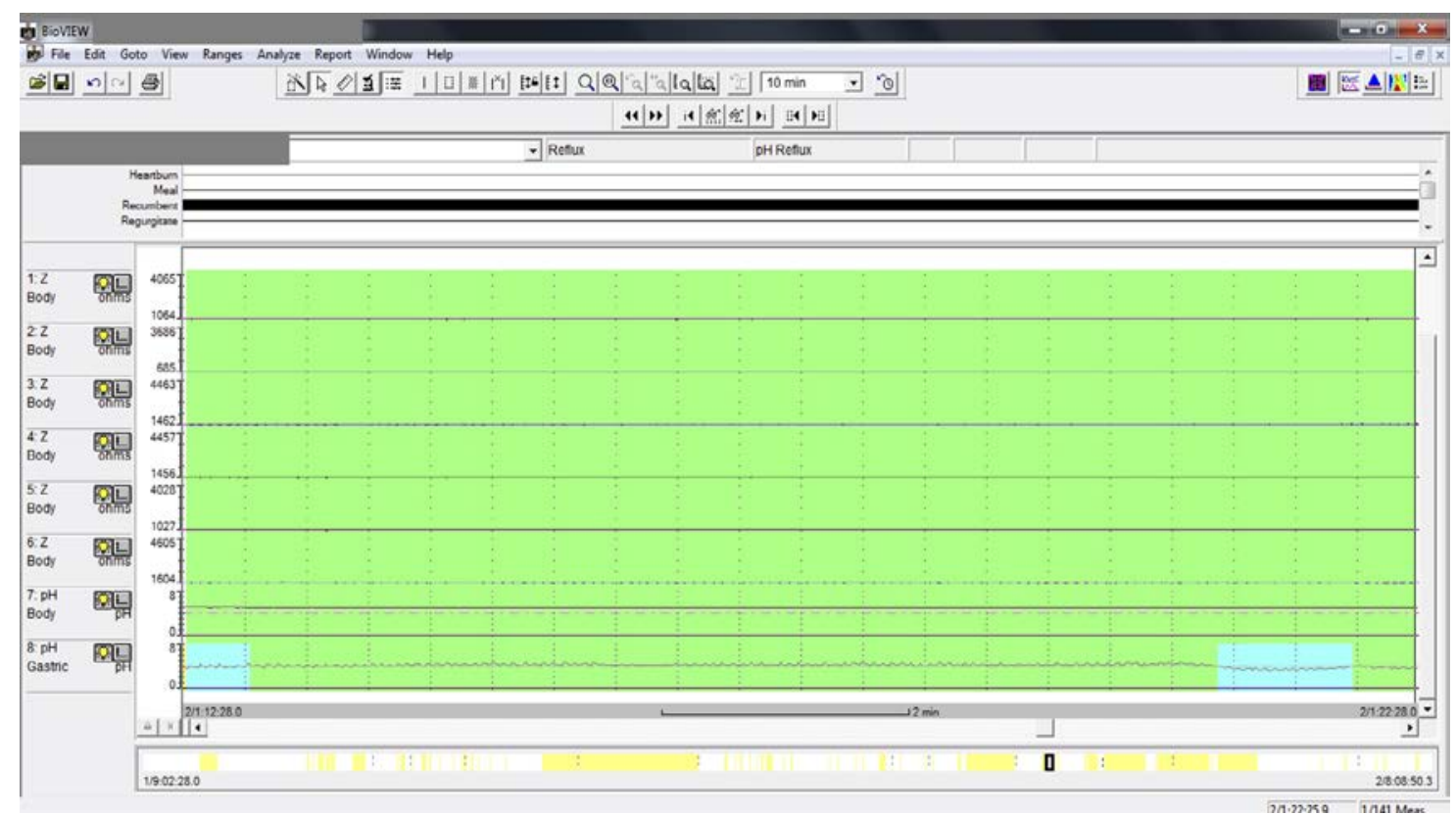

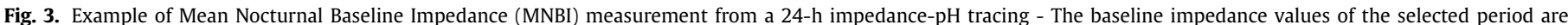
highlighted. The mean low impedance value in channel 6 is computed in three separate 10-min windows.

the daily scenarios during which they experience symptoms. Patients are provided with diaries and asked to record the timing and content of ingested meals, periods of upright and recumbent position and the time of symptoms. They should also be encouraged to maintain a normal level of activity during monitoring.

A standardized meal can be used, with normal values available [109]. Since ingestion of foods or liquids with a $\mathrm{pH}<4.0$ units may mimic reflux events and produce false-positive results [99], acidic foods and drinks should be restricted between meal periods.
Concerning wireless $\mathrm{pH}$ monitoring, patients are also instructed to record the time and type of symptoms that could be related to the capsule, such as chest discomfort, chest pain and dysphagia. Patients are encouraged to pursue their every-day activities, and this is most easily done with the BRAVO wireless monitoring system, especially in children $[110,111]$.

\subsection{Concurrent medications (On or off-PPI monitoring)}

Controversy exists as to whether reflux testing is more useful when performed with patients on- or off-PPI therapy for refrac- 
tory reflux, and, in few patients, a clear diagnosis will only emerge after testing while both off and on medication. For testing patients while off-therapy (7-10 days after discontinuing PPIs), negative $\mathrm{pH}$ monitoring (normal distal esophageal AET and a negative symptom acid reflux association) makes GERD diagnosis very unlikely, and patients with extra-esophageal symptoms require a diagnostic workup for other etiologies. However, it was demonstrated that up to $30 \%$ of patients with the typical reflux syndrome, but without esophageal mucosal erosions at upper endoscopy, may show abnormal findings at MII-pH [45]. In fact, testing a patient offPPI by means of MII-pH allows to assess if there is a pathological number of total reflux events, independently of $\mathrm{pH}$ value, and it is also possible to find a positive symptom-reflux correlation with both weakly acid and weakly alkaline reflux events. Conversely, a negative MII-pH while off-therapy is more reliable than a negative pH-only monitoring, directing the diagnostic workup toward other causes, and enabling cessation of unnecessary PPI therapy.

Reflux monitoring while on PPI, on the other hand, can document an abnormal $\mathrm{pH}$ test in a compliant patient despite assuming medications, leading to an evidence of therapeutic failure (i.e., ongoing acid reflux despite treatment). However, this is uncommon, because on PPI-therapy reflux becomes predominantly non-acid and thus goes undetected by conventional $\mathrm{pH}$ monitoring, with very low likelihood of a positive test. A negative $\mathrm{pH}$ test in treated patients excludes ongoing acid reflux as the cause of their symptoms, but it does not allow a distinction between patients with symptomatic non-acid reflux versus those with no reflux at all. Therefore, impedance-pH monitoring is more informative for patients on acid-suppressing therapy because of its ability to detect weakly acidic and weakly alkaline reflux. Impedance-pH may reveal persistent symptoms associated with acid or nonacid. A negative impedance-pH test of the patient while on medication establishes that the patient's complaints are not generated by GERD, but it does not provide information regarding whether PPIs can be discontinued, as when the test is performed off-PPI. A recent consensus paper provided further insights on the need of testing onor off-therapy suggesting that using MII-pH, reflux should be assessed "off" PPIs in most patients, i.e., those who have an unproven GERD (without peptic lesions or with the lower grades of EE at EGD), extra-esophageal symptoms, under evaluation for anti-reflux surgery or with recurrent/persistent symptoms on PPIs and/or after surgery. Tests should be performed "on" PPI b.i.d. in proven GERD, that is in patients with prior positive $\mathrm{pH}$-testing, LA grades $\mathrm{C}$ and D esophagitis, Barrett's esophagus and peptic strictures [57].

\subsection{Concurrent medications (On or off-PPI monitoring) using Bravo system}

PH testing with Bravo system is generally performed in patients off-PPI therapy. Testing off-therapy is often recommended for patients without esophagitis or extra-esophageal symptoms, in order to confirm or rule out GERD on the basis of esophageal AET and in order to assess the association of typical and atypical symptom with GERD. As PPI therapy does not reduce the number of reflux events, but favors the change of acid into weakly acidic reflux episodes that are not detected by $\mathrm{pH}$ monitoring, wireless $\mathrm{pH}$ test is less useful on PPIs when compared with impedance-pH monitoring $[112,113]$. The use of wireless $48-\mathrm{h}$ pH-metry while on PPI therapy seems useful only to test whether a PPI standard dose is ineffective in achieving complete symptom relief in both ERD or NERD since there is not adequate inhibition of acid [114,115]

\subsection{Normal values of esophageal $\mathrm{pH}$ and impedance data}

The most referenced international threshold for abnormal acid exposure by using conventional catheter-based systems is detec- tion of a $\mathrm{pH}<4.0$ units for more than $4.2 \%$ of the total duration of the study. Moreover, a value $>4.2 \%$ over the whole 24 -h period has been considered valid to separate between normal subjects and GERD patients for many years [116]. However, the experts of the recent Lyon Consensus [57] have proposed that AET $<4 \%$ be considered definitely normal or physiological and $>6 \%$ definitely abnormal, with intermediate values between the above limits being inconclusive. When AET is inconclusive (i.e., between $4 \%$ and $6 \%$ ), adjunctive impedance measures are necessary, such as bolus exposure, MNBI and PSPW. The most referenced value for an abnormal DeMeester composite score (in distinguishing GERD patients from healthy volunteers) is a value greater than 14.7 [74].

Five multicenter studies established normal values for ambulatory 24-h impedance-pH monitoring based on the 95th percentile of normal controls (Table 3). A large U.S. study defined abnormal reflux as $>73$ total reflux episodes [117] and a Belgian-French investigation established an upper limit in the number of total reflux events of 75 [118], which was subsequently reduced to 53 in another study on an exclusive French population [119]. Italian normal values have been obtained on healthy volunteers who underwent impedance-pH monitoring eating a standardized Mediterranean diet [109] and the total number of reflux (95th percentile) was 48 , which increased to 54 by doubling the number of healthy volunteers [45].

The best PSPW index and MNBI value for distinguishing healthy controls from GERD patients have been reported to be $61 \%$ and 2292 Ohms, respectively, by means of ROC analyses performed in 289 GERD patients as compared to 50 non-overweight healthy controls eating a standard Mediterranean diet [101].

\subsection{Normal values of esophageal $\mathrm{pH}$ data using bravo system}

The BRAVO wireless test was originally performed for $48 \mathrm{~h}$, but it is now possible to extend it to $96 \mathrm{~h}$ in order to increase its ability to record pathological reflux and/or establish symptoms/reflux association [120]. This prolonged wireless $\mathrm{pH}$ monitoring has been shown to diagnose GERD in a proportion of patients with a previously negative 24 -h catheter-based monitoring [121,122]. A pathological esophageal acid exposure during the overall 48-h duration is greater than 5.3\%, according to Pandolfino et al. [123]. The presence of an abnormal composite score in either the first or second 24 -h periods has a sensitivity of $93 \%$ and a specificity and positive predictive value of $100 \%$ for diagnosing GERD [123].

\subsection{Symptom-reflux correlation (SI, SAP, SSI)}

One of the primary goals of reflux monitoring, in order to identify and treat GERD patients, is to evaluate the temporal relationship between symptoms and reflux; this relationship is as important as quantifying AET or total reflux number. Actually, three different tools may be used to assess the association between symptoms and reflux episodes: Symptom Index (SI), Symptom Sensitivity Index (SSI), Symptom Association Probability (SAP) [124-126]. However, only SI and SAP are currently used in clinical practice.

The SI is calculated according to Wiener et al. [124] as the percentage of symptoms that is reflux-related, i.e., the percentage of symptoms preceded by a reflux within a 5 -min time window divided by the total number of symptoms. The SI should be determined separately for different symptoms and a positive symptom association is confirmed if the SI is $\geq 50 \%$ (i.e., at least half of the reported symptoms are preceded within a 5-min time window by any reflux episode). The SI has important limitations. In fact, it does not take into account the total number of reflux episodes and therefore a patient with multiple reflux episodes, but only one symptomatic reflux event, will have a SI of $100 \%$. Also, in patients with frequent reflux episodes, random and temporal associations 
Table 3

Normal values for ambulatory 24-h impedance-pH monitoring based on the 95th percentile of healthy controls.

\begin{tabular}{|c|c|c|c|}
\hline & $\begin{array}{l}\text { Catheter-based } \\
\text { pH-metry }\end{array}$ & Impedance-pH monitoring & Wireless pH-metry \\
\hline $\begin{array}{l}\text { Duration of the procedure } \\
\text { (hours) }\end{array}$ & 24 & 24 & $48-96$ \\
\hline $\begin{array}{l}\text { Acid Exposure Time,\% (Abnormal } \\
\text { if) }\end{array}$ & $<4^{74}$ & $\begin{array}{l}<6.3^{117} \\
<5.0^{118} \\
<5.8^{119} \\
<4.0^{109} \\
<4.2^{45} \\
\text { normal }<4 \text {; between } 4 \text { and } 6 \text { inconclusive (gray area); abnormal }>6^{£}\end{array}$ & Abnormal $>5.3^{123}$ \\
\hline Reflux exposure time,\% & $\mathrm{N} / \mathrm{A}$ & $\begin{array}{l}<1.4^{117} \\
<2.0^{118} \\
<2.3^{119}\end{array}$ & \\
\hline Total reflux episodes ( $n$ ) & $\mathrm{N} / \mathrm{A}$ & $\begin{array}{l}<73^{117} \\
<75^{118} \\
<53^{119} \\
<48^{109} \\
<54^{45} \\
\text { normal }<40 \text {; between } 40 \text { and } 80 \text { inconclusive (gray area); abnormal }>80^{£}\end{array}$ & $\mathrm{~N} / \mathrm{A}$ \\
\hline Symptom Index,\% $\%$ & $\geq 50$ & $\geq 50$ & $\geq 50$ \\
\hline $\begin{array}{l}\text { Symptom Association } \\
\text { Probability,\%126 }\end{array}$ & $\geq 95$ & $\geq 95$ & $\geq 95$ \\
\hline $\begin{array}{l}\text { Post-reflux Swallow-induced } \\
\text { Peristaltic Wave Index,\% }\end{array}$ & $\mathrm{N} / \mathrm{A}$ & $>61^{101}$ & $\mathrm{~N} / \mathrm{A}$ \\
\hline $\begin{array}{l}\text { Mean Nocturnal Baseline } \\
\text { Impedance, Ohms }\end{array}$ & $\mathrm{N} / \mathrm{A}$ & $>2292^{101}$ & $\mathrm{~N} / \mathrm{A}$ \\
\hline
\end{tabular}

$\mathrm{N} / \mathrm{A}=$ not applicable.

${ }^{£}$ these values have been established according to expert consensus ${ }^{57}$.

between reflux and symptoms may yield a positive SI in the absence of any true relationship.

The SAP is defined according to Weusten et al. [126] as the statistical relation between symptoms and reflux episodes. The SAP is calculated by dividing the 24-h monitoring data set into consecutive 2-min segments. For each of these 2-min segments, it is determined whether reflux occurred in it, providing the total number of 2-min segments with and without reflux. Subsequently, it is determined whether or not a reflux episode occurred in the 2-min period before each symptom. The SAP tries to evaluate if, from a statistical approach, the reflux events and symptoms during the monitoring period may have occurred by chance. Therefore, only a SAP $>95 \%$ (i.e., the probability of this association having occurred by chance is $<5 \%$ ) is considered positive. Obviously, using impedance monitoring, integration of weakly acidic reflux and weakly alkaline reflux episodes into reflux-symptom association analysis permits to increase the diagnostic yield of both SI and SAP in patients with esophageal and extra-esophageal symptoms as well [127-131].

The recent Lyon Consensus about ambulatory reflux monitoring highlighted that the combination of them provides the best results in terms of clinical relevance. Moreover, these metrics are crucial in the differential diagnosis between $\mathrm{RH}$ and functional heartburn (FH) [57].

\section{Clinical indications}

It is necessary to point out that, given the proven limited sensitivity and specificity of PPI trial and GERD questionnaires in diagnosing GERD [132], and, the fact that almost 70\% of GERD patients do not present mucosal lesions at upper endoscopy [133], prolonged reflux monitoring actually represents the most sensitive tool to document the role of reflux in patients with GERD symptoms [134].

Table 4 reports the current indications for the use of reflux monitoring in daily clinical practice. Reflux testing has generally no indication in the majority of patients with typical GERD symptoms (i.e., heartburn and/or regurgitation) who have adequate symptom relief with medical therapy. Furthermore, patients with compli- cations of reflux including severe EE (LA grade $C$ and D), peptic stricture, or Barrett's esophagus do not require reflux testing to confirm the diagnosis. Conversely, milder grades of EE (LA grade $A$ and B) may require off-PPI reflux testing to confirm the presence of GERD given their frequent association with normal distal esophageal acid exposure and the poor inter-observer agreement among endoscopists in defining this type of lesions [57]. With regards to the use of Bravo wireless system, it should be limited to patients who refuse or do not tolerate catheters, those who have infrequent symptoms, selected patients where there is a strong clinical suspicion of GERD and generally an unsatisfactory response to PPIs, but normal $24 \mathrm{~h}$ reflux testing [122], and it is an option well received by patients when endoscopy is needed at the same time as reflux testing

Off-PPI testing is also recommended in the pre-operative workup of patients candidate for anti-reflux surgery. In fact, an objective diagnosis of GERD is recommended before any intervention [135] and an esophageal manometry is warranted in order to exclude major motility disorders [136]. In particular, MII-pH, including the analysis of novel impedance parameters, is currently representing the test of choice to confirm or exclude typical GERD before surgery [137].

There is no doubt that the role of reflux monitoring is more important in patients with reflux symptoms and without endoscopic mucosal breaks, in whom an objective diagnostic test to define their disease is more likely to be needed [135]. Of note, in these patients the role of additional factors, such as mucosal sensitivity in the pathogenesis of GERD symptoms, has been extensively implicated [138]. Thus, the most efficient technique in correlating symptoms to reflux episodes should be preferred. Indeed, beyond establishing the presence of pathological reflux, ambulatory reflux monitoring can be used to determine whether the patients' symptoms are really associated to reflux. For patient management, positive SI and SAP may suggest the need for a therapeutic intervention (a diagnosis of acid or non-acid $\mathrm{RH}$ can be formulated) and a negative result supports the diagnosis of "functional" disease such as FH or functional non-cardiac chest-pain, i.e., conditions in which symptoms are unlikely to be related to reflux and PPIs should be 
Table 4

Current indications for the use of reflux monitoring in daily clinical practice.

\begin{tabular}{|c|c|c|}
\hline & Reasons & Modality \\
\hline Evaluation of patients with persistent typical & To confirm the presence of GERD & Off-therapy \\
\hline \multirow[t]{2}{*}{ GERD symptoms refractory to medical therapy } & $\begin{array}{l}\text { To determine whether patients' symptoms are really } \\
\text { associated to reflux }\end{array}$ & Off-therapy \\
\hline & $\begin{array}{l}\text { To assess whether persistent symptoms are the result } \\
\text { of incompletely responding GERD (in case of prior } \\
\text { endoscopic or reflux monitoring evidence of GERD) }\end{array}$ & $\begin{array}{l}\text { To assess whether persistent symptoms are } \\
\text { the result of incompletely responding GERD } \\
\text { (in case of prior endoscopic or reflux } \\
\text { monitoring evidence of GERD) }\end{array}$ \\
\hline $\begin{array}{l}\text { Evaluation of patients with milder grades of } \\
\text { erosive esophagitis (LA grades A and B) }\end{array}$ & To confirm the presence of GERD & Off-therapy \\
\hline $\begin{array}{l}\text { Evaluation of patients with esophageal } \\
\text { symptoms suggestive for GERD before surgery }\end{array}$ & To confirm the presence of GERD & Off-therapy \\
\hline Evaluation of patients with NCCP & To assess whether NCCP is associated to reflux & Off-therapy \\
\hline $\begin{array}{l}\text { Evaluation of patients with extra-esophageal } \\
\text { symptoms suggestive for GERD }\end{array}$ & $\begin{array}{l}\text { To assess whether extra-esophageal symptoms are } \\
\text { associated to reflux }\end{array}$ & Off-therapy \\
\hline Evaluation of patients with belching disorders & $\begin{array}{l}\text { To assess the presence of gastric and/or supra-gastric } \\
\text { belching }\end{array}$ & Off-therapy \\
\hline $\begin{array}{l}\text { Evaluation of children with symptoms } \\
\text { suggestive for GERD (particularly in case of } \\
\text { neurological symptoms and low growth) }\end{array}$ & To confirm the presence of GERD & Off-therapy \\
\hline $\begin{array}{l}\text { Evaluation of suspected rumination syndrome } \\
\text { (in combination with high-resolution } \\
\text { esophageal manometry) }\end{array}$ & To confirm the presence of rumination syndrome & Off-therapy \\
\hline
\end{tabular}

stopped. Moreover, MII-pH should be also preferred due to the possibility of measuring the number of reflux episodes, the PSPW index and the MNBI, which have the advantage to be objective and not depending on patient's accuracy in recording symptoms [101]. Indeed, the above two metrics have been shown to be valid parameters to become part of the standard analysis of impedance$\mathrm{pH}$ tracings for improving GERD diagnosis, particularly in patients with endoscopy-negative heartburn, and have redeemed the clinical value of esophageal MII-pH [139].

Acid reflux is not an uncommon cause of non-cardiac chest pain (NCCP), which is, in fact, more frequently reported by patients who also experience heartburn and regurgitation [140]. Although in the largest series up to $60 \%$ of patients suffering from NCCP present evidence of GERD [141], this association may not exclude other causes of NCCP and it should be taken into consideration the complex relationship between heart - microvascular angina and/or coronary spasm - and esophageal symptoms such as chest pain, both elicited, in experimental investigations, by intra-esophageal acid perfusions [125]. Wireless $\mathrm{pH}$ monitoring may be particularly useful on those occasions when chest pain is infrequent [142]. Abnormalities of esophageal motility have been shown to be pathogenic only in a minority of patients with NCCP [143] and the diagnostic role of upper GI endoscopy appears to be very low even in treatment-naive patients [144]. However, several randomized and controlled studies have reported $70 \%-90 \%$ of NCCP patients with an abnormal pH-test, in terms of both pathological AET or positive reflux-symptom association [145,146].

A group of patients in whom wireless $\mathrm{pH}$ monitoring has been shown useful is achalasia after successful treatment in order to diagnose GERD [147]. This is due to the fact that, in these patients, day-to-day variability of esophageal AET is much greater than in other patients.

Evaluation of patients with extra-esophageal symptoms suggestive for GERD remains a major challenge for the gastroenterologist. Although, with different strength depending upon the various symptoms, an association with GERD is a common finding in patients with asthma, chronic cough (CC) and laryngitis, it has to be borne in mind that all these disorders are highly prevalent in the general population and, therefore, may well coexist in our patients without a cause-effect relationship. The large majority of patients with extra-esophageal symptoms (> 80\%) will exhibit upper endoscopy findings within the normal range, but their response to
PPI treatments results to be substantially lower and frequently disappointing, in particular in absence of a rigorous patient selection. The more recent guidelines of the American College of Gastroenterology for the diagnosis and management of GERD report as a conditional recommendation - that reflux monitoring should be considered as first approach in patients with extra-esophageal symptoms who do not present concomitant typical symptoms of GERD and a PPI trial should be prescribed only in those with objective evidence of GERD [148]. Chronic cough is particularly suitable to be studied by assessing the symptom-reflux association and baseline impedance $[64,149]$. It should be reminded, however, that evaluation of cough-reflux association needs objective cough recording with manometry [147], otherwise a positive association does not allow to distinguish the sequence cough-reflux from the one reflux-cough.

A further indication for reflux testing is represented by belching disorders. Air is ingested and transported to the stomach with swallowing [150]. Several studies have shown that gastric distention induced by inflation of the stomach with air may trigger TLESRs $[151,152]$. These TLESRs allow ingested air to be vented and this serves as a physiological protection against dilatation of the stomach. However, TLESRs are also the most important mechanism through which liquid gastric contents can reflux into the esophagus [153]. Thus, belching and gastroesophageal reflux share the same mechanism. Indeed, almost 50\% of patients with GERD complain of excessive belching $[154,155]$. Moreover, it has long been described that, in some cases, the cause of excessive belching is not due to the gastric belching mechanism, but is instead caused by a rapid process of air entry by "sucking" or "pushing" air from the mouth or pharynx into the esophagus and then expelling it with abdominal straining [156]. This process can now be easily observed using intra-esophageal impedance, and has been termed supra-gastric belching (SGB), since the gas does not originate from the stomach, and indeed frequently does not involve gas entry into the stomach [157]. Patients with SGB often complain of excessive belching with a severe impact on quality of life, and belching can occur hundreds of times per day [158]. Recently, SGB was retrospectively studied in a large number of patients and healthy subjects [159]. In this study, it was established that 13 SGB can be considered the upper limit of normality in healthy controls; excessive SGB was found in $3.4 \%$ of them and it rarely occurred in isolation without other symptoms; it was observed in both patients 
with GERD and in patients with esophageal hypomotility and, in only the same cases, contributed significantly to GER. Two recent interventional studies found that cognitive behavioral therapy reduced the number of SGB, as assessed by MII-pH, and improved social and daily activities [160,161]. Thus, the authors concluded that careful analysis of MII-pH allows identification of a subgroup of GERD patients with acid reflux predominantly driven by SGB. In these patients, cognitive behavioral therapy (CBT) can reduce esophageal acid exposure.

Finally, one of the most common use of reflux monitoring is the evaluation of patients with persistent typical GERD symptoms despite medical therapy. Refractory heartburn can be defined as the presence of heartburn that does not respond to at least 8-weeks of double-dose acid suppressing medications [162]. It has been estimated that failure to control symptoms occurs in $20 \%$ of patients optimally treated with a PPI and this phenomenon is strictly dependent on the frequent misuse of PPI therapy, which increases also the occurrence of adverse events attributed to these drugs [162-165]. In the assessment of such patients, reflux monitoring attempts to discern whether ongoing symptoms are the result of incompletely treated GERD or are due to an etiology unrelated to GERD. In this context, it is strongly debated whether to test on or off therapy. Off-PPI testing should be preferred in those patients without a previous diagnosis of GERD (endoscopy and/or reflux testing), especially if they have a low pre-test probability of GERD, whereas on-PPI testing should be reserved for those who already have a diagnosis of GERD [166]. Indeed, performing reflux monitoring off-therapy may show whether the patient truly presents a reflux disease or not (as discussed above for endoscopy-negative patients), whereas testing on-therapy may reveal: (a) an ongoing abnormal esophageal acid exposure requiring an unproven therapeutic intervention (PPI escalation or switch to other PPIs, addition of $\mathrm{H}_{2}$ antagonists or antacid/alginate medication or surgery); (b) adequate acid control, but a positive symptom-reflux correlation helping in identifying patients with esophageal acid $\mathrm{RH}$ or with esophageal acid and/or non-acidic RH; and (c) adequate acid control, but a negative symptom-reflux correlation suggesting that reflux is less likely to be the cause of symptoms (FH) and with the mandatory indication of stopping PPI therapy. In particular, $\mathrm{pH}-$ impedance offers the opportunity to clarify all possible scenarios and, for this reason, is considered by many experts as the most sensitive technique to investigate patients with symptoms refractory to PPI therapy [164]. Of note, however, the use of the wireless $\mathrm{pH}$ system for 4-day recordings should be of value in some cases. Actually, a recent impedance-pH study shows that lack of improvement of impaired chemical clearance, but not ineffective acid suppression, is the key pathogenic mechanism of PPI-refractory refluxrelated heartburn [104], suggesting surgery as the most logical therapeutic option. Accordingly, a recent randomized trial of medical versus surgical treatment for refractory heartburn observed that a systematic workup including the use of MII-pH may reveal patients with truly PPI-refractory and reflux-related heartburn, for whom surgery was superior to medical treatment [70] and this is robust confirmation that patients with RH can benefit from surgical therapy as much as those with abnormal AET.

\section{Conflict of interest}

Edoardo Savarino received lecture fee from Medtronic.

\section{CRediT authorship contribution statement}

Edoardo Savarino: Conceptualization, Data curation, Formal analysis, Writing - original draft, Writing - review \& editing. Marzio Frazzoni: Conceptualization, Data curation, Formal analysis, Writing - original draft, Writing - review \& editing.
Elisa Marabotto: Conceptualization, Data curation, Formal analysis, Writing - original draft, Writing - review \& editing. Patrizia Zentilin: Conceptualization, Data curation, Formal analysis, Writing - original draft, Writing - review \& editing. Paola Iovino: Conceptualization, Data curation, Formal analysis, Writing - original draft, Writing - review \& editing. Mario Costantini: Conceptualization, Data curation, Formal analysis, Writing - original draft, Writing - review \& editing. Salvatore Tolone: Conceptualization, Data curation, Formal analysis, Writing - original draft, Writing - review \& editing. Edda Battaglia: Conceptualization, Data curation, Formal analysis, Writing - original draft, Writing - review \& editing. Michele Cicala: Conceptualization, Data curation, Formal analysis, Writing - original draft, Writing - review \& editing. Paolo Usai-Satta: Conceptualization, Data curation, Formal analysis, Writing - original draft, Writing - review \& editing. Nicola de Bortoli: Conceptualization, Data curation, Formal analysis, Writing - original draft, Writing - review \& editing. Roberto Penagini: Conceptualization, Data curation, Formal analysis, Writing - original draft, Writing - review \& editing. Vincenzo Savarino: Conceptualization, Data curation, Formal analysis, Writing - original draft, Writing review \& editing.

\section{Funding}

None.

\section{References}

[1] Vakil N, van Zanten SV, Kahrilas P, et al. The Montreal definition and classification of gastroesophageal reflux disease: a global evidence-based consensus. Am J Gastroenterol 2006;101:1900-20.

[2] Savarino E, Giacchino M, Savarino V. Dysmotility and reflux disease. Curr Opin Otolaryngol Head Neck Surg 2013;21:548-56

[3] Tolone S, De Bortoli N, Marabotto E, et al. Esophagogastric junction contractility for clinical assessment in patients with GERD: a real added value? Neurogastroenterol Motil 2015;27:1423-31.

[4] Tolone S, de Cassan C, de Bortoli N, et al. Esophagogastric junction morphology is associated with a positive impedance-pH monitoring in patients with GERD. Neurogastroenterol Motil 2015:27:1175-82.

[5] Savarino E, Gemignani L, Pohl D, et al. Oesophageal motility and bolus transit abnormalities increase in parallel with the severity of gastro-oesophageal reflux disease. Aliment Pharmacol Ther 2011;34:476-86.

[6] Gyawali CP, Sifrim D, Carlson DA, et al. Ineffective esophageal motility: concepts, future directions, and conclusions from the Stanford 2018 symposium. Neurogastroenterol Motil 2019;31:e13584.

[7] Roman S, Holloway R, Keller J, et al. Validation of criteria for the definition of transient lower esophageal sphincter relaxations using high-resolution manometry. Neurogastroenterol Motil 2017;29(2). doi:10.1111/nmo.12920.

[8] van Malenstein H, Farré R, Sifrim D. Esophageal dilated intercellular spaces (DIS) and nonerosive reflux disease. Am J Gastroenterol 2008;103:1021-8.

[9] Savarino E, Zentilin P, Mastracci L, et al. Microscopic esophagitis distinguishes patients with non-erosive reflux disease from those with functional heartburn. J Gastroenterol 2013:48:473-82.

[10] Zentilin P, Savarino V, Mastracci L, et al. Reassessment of the diagnostic value of histology in patients with GERD, using multiple biopsy sites and an appropriate control group. Am J Gastroenterol 2005; 100:2299-306.

[11] Caviglia R, Ribolsi M, Maggiano N, et al. Dilated intercellular spaces of esophageal epithelium in nonerosive reflux disease patients with physiological esophageal acid exposure. Am J Gastroenterol 2005;100:543-8.

[12] Woodland P, Ooi JLS, Grassi F, et al. Superficial esophageal mucosal afferent nerves may contribute to reflux hypersensitivity in nonerosive reflux disease. Gastroenterology 2017;153:1230-9.

[13] Nikaki K, Woodland P, Lee C, et al. Esophageal mucosal innervation in functional heartburn: closer to healthy asymptomatic subjects than to non-erosive reflux disease patients. Neurogastroenterol Motil 2019;31:e13667.

[14] Aziz Q, Fass R, Gyawali CP, et al. Functional esophageal disorders. Gastroenterology 2016:150:1368-79 pii: S0016-5085(16)00178-5.

[15] Carlson DA, Gyawali CP, Roman S, et al. Esophageal hypervigilance and visceral anxiety are contributors to symptom severity among patients evaluated with high-resolution esophageal manometry. Am J Gastroenterol 2020; $115: 367-75$

[16] van Herwaarden MA, Samsom M, Smout AJ. The role of hiatus hernia in gastro-oesophageal reflux disease. Eur J Gastroenterol Hepatol 2004;16:831-5.

[17] Pandolfino JE, Kim H, Ghosh SK, et al. High-resolution manometry of the EGJ: an analysis of crural diaphragm function in GERD. Am J Gastroenterol 2007; 102:1056-63.

[18] De Giorgi F, Palmiero M, Esposito I, et al. Pathophysiology of gastro-oesophageal reflux disease. Acta Otorhinolaryngol Ital 2006;26(5):241-6. 
[19] Hoshino M, Sundaram A, Mittal SK. Role of the lower esophageal sphincter on acid exposure revisited with high-resolution manometry. J Am Coll Surg 2011:213:743-50.

[20] Nicodème F, Pipa-Muniz M, Khanna K, et al. Quantifying esophagogastric junction contractility with a novel HRM topographic metric, the EGJ-Contractile Integral: normative values and preliminary evaluation in PPI non-responders. Neurogastroenterol Motil 2014;26:353-60.

[21] Rengarajan A, Gyawali CP. High-resolution manometry can characterize esophagogastric junction morphology and predict esophageal reflux burden. J Clin Gastroenterol 2020;54:22-7.

[22] Mittal RK, Holloway RH, Penagini R, et al. Transient lower esophageal sphincter relaxation. Gastroenterology 1995;109(2):601-10.

[23] Trudgill NJ, Riley SA. Transient lower esophageal sphincter relaxations are no more frequent in patients with gastroesophageal reflux disease than in asymptomatic volunteers. Am J Gastroenterol 2001;96: 2569-2574.

[24] Sifrim D, Holloway R, Silny J, et al. Composition of the postprandial refluxate in patients with gastroesophageal reflux disease. Am J Gastroenterol 2001;96(3):647-55.

[25] Sloan S, Rademaker AW, Kahrilas PJ. Determinants of gastroesophageal junction incompetence: hiatal hernia, lower esophageal sphincter, or both? Ann Intern Med 1992;117:977-82.

[26] Curci JA, Melman LM, Thompson RW, et al. Elastic fiber depletion in the supporting ligaments of the gastroesophageal junction: a structural basis for the development of hiatal hernia. J Am Coll Surg 2008;207(2):191-6. doi:10.1016/j.jamcollsurg.2008.02.036.

[27] Emerenziani S, Habib FI, Ribolsi M, et al. Effect of hiatal hernia on proximal oesophageal acid clearance in gastro-oesophageal reflux disease patients. Aliment Pharmacol Ther 2006;23:751-7.

[28] Sloan S, Kahrilas PJ. Impairment of esophageal emptying with hiatal hernia. Gastroenterology 1991;100:596-605.

[29] Rengarajan A, Bolkhir A, Gor P, et al. Esophagogastric junction and esophageal body contraction metrics on high-resolution manometry predict esophageal acid burden. Neurogastroenterol Motil 2018;30(5):e13267.

[30] Gyawali CP, Roman S, Bredenoord AJ, et al. Classification of esophageal motor findings in gastro-esophageal reflux disease: conclusions from an international consensus group. Neurogastroenterol Motil 2017;29(12). doi:10.1111/ nmo.13104.

[31] Simrén M, Silny J, Holloway R, et al. Relevance of ineffective oesophageal motility during oesophageal acid clearance. Gut 2003;52(6):784-90. doi:10. 1136/gut.52.6.784.

[32] Gourcerol G, Benanni Y, Boueyre E, et al. Influence of gastric emptying on gastro-esophageal reflux: a combined $\mathrm{pH}$-impedance study. Neurogastroenterol Motil 2013;25(10):800-634.

[33] Jehangir A, Parkman HP. Reflux symptoms in gastroparesis: correlation with gastroparesis symptoms, gastric emptying, and esophageal function testing. J Clin Gastroenterol 2020;54(5):428-38.

[34] Fletcher J, Wirz A, Young J, et al. Unbuffered highly acidic gastric juice exists at the gastroesophageal junction after a meal. Gastroenterology 2001; 121(4):775-83.

[35] Iovino P, Angrisani L, Galloro, et al. Proximal stomach function in obesity with normal or abnormal oesophageal acid exposure. Neurogastroenterol Motil 2006;18:425-32.

[36] de Vries DR, van Herwaarden MA, Smout AJ, et al. Gastroesophageal pressure gradients in gastroesophageal reflux disease: relations with hiatal hernia, body mass index, and esophageal acid exposure. Am J Gastroenterol 2008;103(6):1349-54.

[37] El-Serag H. Role of obesity in GORD-related disorders. Gut 2008;57(3):281-4.

38] Savarino E, Zentilin P, Marabotto E, et al. Overweight is a risk factor for both erosive and non-erosive reflux disease. Dig Liver Dis 2011;43:940-5.

[39] Savarino E, Tutuian R, Zentilin P, et al. Characteristics of reflux episodes and symptom association in patients with erosive esophagitis and nonerosive reflux disease: study using combined impedance-pH off therapy. Am J Gastroenterol 2010;105:1053-61.

[40] Bredenoord AJ, Weusten BL, Timmer R, et al. Addition of esophageal impedance monitoring to $\mathrm{pH}$ monitoring increases the yield of symptom association analysis in patients off PPI therapy. Am J Gastroenterol 2006;101(3):453-9.

[41] Hemmink GJ, Bredenoord AJ, Weusten BL, et al. Esophageal pH-impedance monitoring in patients with therapy-resistant reflux symptoms: 'on' or 'off proton pump inhibitor? Am J Gastroenterol 2008;103(10): 2446-2453.

[42] Zerbib F, Roman S, Ropert A, et al. Esophageal pH-impedance monitoring and symptom analysis in GERD: a study in patients off and on therapy. Am J Gastroenterol 2006;101:1956-63.

[43] Savarino E, Marabotto E, Zentilin P, et al. The added value of impedance-pH monitoring to Rome III criteria in distinguishing functional heartburn from non-erosive reflux disease. Dig Liver Dis 2011;43:542-7.

[44] Savarino E, Zentilin P, Frazzoni M, et al. Characteristics of gastro-esophageal reflux episodes in Barrett's esophagus, erosive esophagitis and healthy volunteers. Neurogastroenterol Motil 2010;22:1061-e280.

[45] Savarino E, Zentilin P, Tutuian R, et al. The role of nonacid reflux in NERD: lessons learned from impedance-pH monitoring in 150 patients off therapy. Am J Gastroenterol 2008;103:2685-93.

[46] Weijenborg P.W., Bredenoord A. J How reflux causes symptoms: reflux perception in gastroesophageal reflux disease. Best Pract Res Cl Ga 2013; 27: 353-64
[47] Cicala M, Emerenziani S, Caviglia R, et al. Intra-oesophageal distribution and perception of acid reflux in patients with non-erosive gastro-oesophageal reflux disease. Aliment Pharmacol Ther 2003;18:605-13.

[48] Sifrim D, Zerbib F. Diagnosis and management of patients with reflux symptoms refractory to proton pump inhibitors. Gut 2012;61:1340-54.

[49] Emerenziani S, Sifrim D, Habib FI, et al. Presence of gas in the refluxate enhances reflux perception in non-erosive patients with physiological acid exposure of the oesophagus. Gut 2008;57:443-7.

[50] Nakagawa K, Sawada A, Hoshikawa Y, et al. Persistent postprandial regurgitation vs. rumination in patients with refractory gastroesophageal reflux disease symptoms: identification of a distinct rumination pattern using ambulatory impedance-pH monitoring. Am J Gastroenterol 2019;114:1248-55.

[51] Woodland P, Sifrim D. Esophageal mucosal integrity in nonerosive reflux disease. J Clin Gastroenterol 2014;48:6-12.

[52] Patel A, Hasak S, Nix BD, et al. Genetic risk factors for perception of symptoms in GERD: an observational cohort study. Aliment Pharmacol Ther 2018;47(2):289-97. doi:10.1111/apt.14414.

[53] Gyawali CP, Azagury DE, Chan WW, et al. Nonerosive reflux disease: clinical concepts. Ann N Y Acad Sci 2018;1434:290-303.

[54] de Bortoli N, Ottonello A, Zerbib F, et al. Between GERD and NERD: the relevance of weakly acidic reflux. Ann N Y Acad Sci 2016;1380:218-29.

[55] Savarino E, Pohl D, Zentilin P, et al. Functional heartburn has more in common with functional dyspepsia than with non-erosive reflux disease. Gut 2009;58:1185-91.

[56] de Bortoli N, Frazzoni L, Savarino EV, et al. Functional heartburn overlaps with irritable bowel syndrome more often than GERD. Am J Gastroenterol 2016;111:1711-17.

[57] Gyawali CP, Kahrilas PJ, Savarino E, et al. Modern diagnosis of GERD: the Lyon Consensus. Gut 2018;67:1351-62.

[58] Gyawali CP, de Bortoli N, Clarke J, et al. Indications and interpretation of esophageal function testing. Ann N Y Acad Sci 2018;1434:239-53.

[59] Savarino E, Marabotto E, Bodini G, et al. Advancements in the use of manometry and impedance testing for esophageal functional disorders. Expert Rev Gastroenterol Hepatol 2019;13:425-35.

[60] Vaezi MF, Katzka D, Zerbib F. Extraesophageal symptoms and diseases attributed to GERD: where is the pendulum swinging now? Clin Gastroenterol Hepatol 2018;16:1018-29.

[61] Francis DO, Slaughter JC, Ates F, et al. Airway hypersensitivity, reflux, and phonation contribute to chronic cough. Clin Gastroenterol Hepatol 2016;14:378-84.

[62] Patel DA, Blanco M, Vaezi MF. Laryngopharyngeal reflux and functional laryngeal disorder: perspective and common practice of the general gastroenterologist. Gastroenterol Hepatol N Y 2018;14:512-20.

[63] Ghisa M, Della Coletta M, Barbuscio I, et al. Updates in the field of non-esophageal gastroesophageal reflux disorder. Expert Rev Gastroenterol Hepatol 2019;13:827-38.

[64] Ribolsi M, Savarino E, De Bortoli N, et al. Reflux pattern and role of impedance-pH variables in predicting PPI response in patients with suspected GERD-related chronic cough. Aliment Pharmacol Ther 2014:40:966-73.

[65] Savarino E, Carbone R, Marabotto E, et al. Gastro-oesophageal reflux and gastric aspiration in idiopathic pulmonary fibrosis patients. Eur Respir J 2013:42:1322-31.

[66] Savarino E, Bazzica M, Zentilin P, et al. Gastroesophageal reflux and pulmonary fibrosis in scleroderma: a study using $\mathrm{pH}$-impedance monitoring. Am J Respir Crit Care Med 2009;179:408-13.

[67] de Leone A, Tonini M, Dominici P, et al., EMERGE Study Group The proton pump inhibitor test for gastroesophageal reflux disease: optimal cut-off value and duration. Dig Liver Dis 2010;42(11):785-90.

[68] Pace F. Pace M. The proton pump inhibitor test and the diagnosis of gastroesophageal reflux disease. Expert Rev Gastroenterol Hepatol 2010;4(4):423-7.

[69] Savarino V, Dulbecco P, de Bortoli N, et al. The appropriate use of proton pump inhibitors (PPIs): need for a reappraisal. Eur J Intern Med 2017;37:19-24.

[70] Spechler SJ, Hunter JG, Jones KM, et al. Randomized Trial of Medical versus Surgical Treatment for Refractory Heartburn. N Engl J Med 2019;381:1513-23.

[71] Harnik IG. In the clinic. Gastroesophageal reflux disease. Ann Intern Med 2015;163(1) ITC1.

[72] Roman S, Gyawali CP, Savarino E, et al. Ambulatory reflux monitoring for diagnosis of gastro-esophageal reflux disease: update of the Porto consensus and recommendations from an international consensus group. Neurogastroenterol Motil 2017;29:1-15.

[73] Savarino E, de Bortoli N, Bellini M, et al. Practice guidelines on the use of esophageal manometry - a GISMAD-SIGE-AIGO medical position statement. Dig Liver Dis 2016;48:1124-35.

[74] Johnson LF, DeMeester TR. Twenty-four-hour $\mathrm{pH}$ monitoring of the distal esophagus. A quantitative measure of gastroesophageal reflux. Am J Gastroenterol 1974;62:325-32.

[75] Sifrim D, Castell D, Dent J, et al. Gastro-oesophageal reflux monitoring: review and consensus report on detection and definitions of acid, non-acid, and gas reflux. Gut 2004;53(7):1024-31. doi:10.1136/gut.2003.033290.

[76] Roman S, Bruley des Varannes S, Pouderoux P, et al., ; Consortium de Recherche Indépendant sur le Traitement et l'Exploration du Reflux gastro-oesophagien et de l'Endobrachyoesophage (CRITERE) Ambulatory 24-h oesophageal impedance-pH recordings: reliability of automatic analysis for gastro-oesophageal reflux assessment. Neurogastroenterol Motil 2006;18(11):978-86. 
[77] Zentilin P, Dulbecco P, Savarino E, et al. Combined multichannel intraluminal impedance and pH-metry: a novel technique to improve detection of gastro-oesophageal reflux literature review. Dig Liver Dis 2004;36: $565-569$

[78] van Rhijn BD, Kessing BF, Smout AJPM, et al. Oesophageal baseline impedance values are decreased in patients with eosinophilic oesophagitis. United Eur Gastroenterol J 2013:1(4):242-8.

[79] Zentilin P, Savarino V, Marabotto E, et al. Esophageal baseline impedance levels allow the identification of esophageal involvement in patients with systemic sclerosis. Semin Arthritis Rheum 2018;47:569-74.

[80] Pandolfino JE, Schreiner MA, Lee TJ, et al. Comparison of the Bravo wireless and Digitrapper catheter-based $\mathrm{pH}$ monitoring systems for measuring esophageal acid exposure. Am J Gastroenterol 2005;100(7):1466-76.

[81] Dobhan R, Castell DO. Prolonged intraesophageal $\mathrm{pH}$ monitoring with 16-hr overnight recording. Comparison with "24-hr" analysis. Dig Dis Sci 1992;37:857-64

[82] Emde C, Garner A, Blum AL. Technical aspects of intraluminal pH-metry in man: current status and recommendations. Gut 1987;28:1177-88.

[83] Geus WP, Smout AJ, Kooiman JC, et al. Glass and antimony electrodes for long-term pH monitoring: a dynamic in vitro comparison. Eur J Gastroenterol Hepatol 1995;7(1):29-35.

[84] Kahrilas PJ, Quigley EM. Clinical esophageal pH recording: a technical review for practice guideline development. Gastroenterology 1996;110:1982-96.

[85] Duroux P, Emde C, Bauerfeind P, et al. The ion sensitive field effect transistor (ISFET) $\mathrm{pH}$ electrode: a new sensor for long term ambulatory $\mathrm{pH}$ monitoring. Gut 1991;32:240-5.

[86] Dolder M, Tutuian R. Laboratory based investigations for diagnosing gastroesophageal reflux disease. Best Pract Res Clin 2010;24:787-98.

[87] Anggiansah A, Sumboonnanonda K, Wang J, et al. Significantly reduced acid detection at $10 \mathrm{~cm}$ compared to $5 \mathrm{~cm}$ above lower esophageal sphincter in patients with acid reflux. Am J Gastroenterol 1993;88(6):842-6.

[88] Klauser AG, Schindlbeck NE, Müller-Lissner SA. Esophageal 24-h pH monitoring: is prior manometry necessary for correct positioning of the electrode? Am J Gastroenterol 1990;85:1463-7.

[89] Mattox HE 3rd, Richter JE, Sinclair JW, et al. Gastroesophageal pH step-up inaccurately locates proximal border of lower esophageal sphincter. Dig Dis Sci 1992;37(8):1185-91.

[90] Mauro A, Franchina M, Consonni D, et al. Lower oesophageal sphincter identification for gastro-oesophageal reflux monitoring: the step-up method revisited with use of basal impedance. United Eur Gastroenterol J 2019;7:1373-9.

[91] Lacy BE, O'Shana T, Hynes M, et al. Safety and tolerability of transoral Bravo capsule placement after transnasal manometry using a validated conversion factor. Am J Gastroenterol 2007;102:24-32.

[92] Saritas Yuksel E, Higginbotham T, Slaughter JC, et al. Use of direct, endoscopic-guided measurements of mucosal impedance in diagnosis of gastroesophageal reflux disease. Clin Gastroenterol Hepatol 2012;10:1110-16.

[93] Ates F, Yuksel ES, Higginbotham T, et al. Mucosal impedance discriminates GERD from non-GERD conditions. Gastroenterology 2015;148:334-43.

[94] Savarino E, Zentilin P, Savarino V, et al. Functional testing: pharyngeal $\mathrm{pH}$ monitoring and high-resolution manometry. Ann N Y Acad Sci 2013;1300:226-35.

[95] Becker V, Graf S, Schlag C, et al. First agreement analysis and day-today comparison of pharyngeal $\mathrm{pH}$ monitoring with $\mathrm{pH} /$ impedance monitoring in patients with suspected laryngopharyngeal reflux. J Gastrointest Surg 2012;16:1096-101.

[96] Worrell SG, DeMeester SR, Greene CL, et al. Pharyngeal pH monitoring better predicts a successful outcome for extraesophageal reflux symptoms after antireflux surgery. Surg Endosc 2013;27(11):4113-18.

[97] Bredenoord AJ, Weusten BLAM, Timmer R, et al. Reproducibility of multichannel intraluminal electrical impedance monitoring of gastroesophageal reflux. Am J Gastroenterol 2005;100(2):265-9. doi:10.1111/j.1572-0241.2005.41084.x.

[98] Spencer J. Prolonged pH recording in the study of gastro oesophageal reflux. Br J Surg 1969;56:9-12.

[99] Agrawal A, Tutuian R, Hila A. Ingestion of acidic foods mimics gastroesophageal reflux during pH monitoring. Dig Dis Sci 2005;50:1916-20.

[100] de Bortoli N, Martinucci I, Savarino EV, et al. Manually calculated oesophageal bolus clearance time increases in parallel with reflux severity at impedance-pH monitoring. Dig Liver Dis 2015;47:1027-32.

[101] Frazzoni M, Savarino E, de Bortoli N, et al. Analyses of the Post-reflux Swallow-induced Peristaltic Wave Index and Nocturnal Baseline Impedance Parameters Increase the Diagnostic Yield of Impedance-pH Monitoring of Patients with Reflux Disease. Clin Gastroenterol Hepatol 2016;14:40-6.

[102] Frazzoni M, de Bortoli N, Frazzoni L, et al. Impairment of chemical clearance and mucosal integrity distinguishes hypersensitive esophagus from functional heartburn. J Gastroenterol 2017;52:444-51.

[103] Frazzoni M, de Bortoli N, Frazzoni L, et al. The added diagnostic value of postreflux swallow-induced peristaltic wave index and nocturnal baseline impedance in refractory reflux disease studied with on-therapy impedancepH monitoring. Neurogastroenterol Motil 2017;29. doi:10.1111/nmo.12947.

[104] Frazzoni M, Frazzoni L, Tolone S, et al. Lack of improvement of impaired chemical clearance characterizes PPI-refractory reflux-related heartburn. Am J Gastroenterol 2018;113:670-6.

[105] Frazzoni M, Penagini R, Frazzoni L, et al. Role of reflux in the pathogenesis of eosinophilic esophagitis: comprehensive appraisal with off- and on PPI impedance-pH monitoring. Am J Gastroenterol 2019;114:1606-13.

[106] de Bortoli N, Martinucci I, Savarino E, et al. Association between baseline impedance values and response proton pump inhibitors in patients with heartburn. Clin Gastroenterol Hepatol 2015;13:1082-8.

[107] Frazzoni L, Frazzoni M. De Bortoli N, et al. Postreflux swallow-induced peristaltic wave index and nocturnal baseline impedance can link PPI-responsive heartburn to reflux better than acid exposure time. Neurogastroenterol Motil 2017;29:e13116.

[108] Patel A, Wang D, Sainani N, et al. Distal mean nocturnal baseline impedance on pH-impedance monitoring predicts reflux burden and symptomatic outcome in gastro-oesophageal reflux disease. Aliment Pharmacol Ther 2016:44:890-8.

[109] Zentilin P, Iiritano E, Dulbecco P, et al. Normal values of 24-h ambulatory intraluminal impedance combined with pH-metry in subjects eating a Mediterranean diet. Dig Liver Dis 2006;38:226-32.

[110] Grigolon A, Bravi I, Cantù P, et al. Wireless pH monitoring: better tolerability and lower impact on daily habits. Dig Liver Dis 2007;39:720-4.

[111] Pandolfino JE. Bravo capsule $\mathrm{pH}$ monitoring. Am J Gastroenterol 2005:100:8-10.

[112] Tolone S, Furnari M, de Bortoli N, et al. Data on symptom association analysis in patients undergoing endoscopic therapy is useful to better define a successful therapeutic approach. Am J Gastroenterol 2015;110(11):1621.

[113] de Bortoli N, Furnari M, Tolone S, et al. A more in-depth evaluation of impedance-pH could assist in distinguishing reflux-related from reflux-unrelated heartburn. J Neurogastroenterol Motil 2015;21(4):621-2.

[114] Roman S, Mion F, Zerbib F, et al. Wireless pH capsule: yield in clinical practice. Endoscopy 2012;44(3):270-6.

[115] Kandulski A, Peitz U, Mönkemüller K, et al. GERD assessment including pH metry predicts a high response rate to PPI standard therapy. BMC Gastroenterol 2013:13:12-19.

[116] de Bortoli N, Martinucci I, Bertani L, et al. Esophageal testing: what we have so far. World J Gastrointest Pathophysiol 2016;7:72-85.

[117] Shay S, Tutuian R, Sifrim D, et al. Twenty-four hour ambulatory simultaneous impedance and $\mathrm{pH}$ monitoring: a multicenter report of normal values from 60 healthy volunteers. Am J Gastroenterol 2004;99:1037-43.

[118] Zerbib F, Bruley des Varannes S, Roman S, et al. Normal values and dayto-day variability of 24-h ambulatory oesophageal impedance-pH monitoring in a Belgian-French cohort of healthy subjects. Aliment Pharmacol Ther 2005;22:1011-21.

[119] Zerbib F, Roman S, Bruley des Varannes S, et al. Normal values of pharyngeal and esophageal 24-hour pH impedance in individuals on and off therapy and interobserver reproducibility. Clin Gastroenterol Hepatol 2013;11:366-72.

[120] Grigolon A, Consonni D, Bravi I, et al. Diagnostic yield of 96-h wireless pH monitoring and usefulness in patients' management. Scand J Gastroenterol 2011;46(5):522-30.

[121] Sweis R, Fox M, Anggiansah A, et al. Prolonged, wireless pH-studies have a high diagnostic yield in patients with reflux symptoms and negative 24-h catheter-based pH-studies. Neurogastroenterol Motil 2011;23(5):419-26.

[122] Penagini R, Sweis R, Mauro A, et al. Inconsistency in the diagnosis of functional heartburn: usefulness of prolonged wireless $\mathrm{pH}$ monitoring in patients with proton pump inhibitor refractory gastroesophageal reflux disease. J Neurogastroenterol Motil 2015;21(2):265-7.

[123] Pandolfino JE, Richter JE, Ours T, et al. Ambulatory esophageal pH monitoring using a wireless system. Am J Gastroenterol 2003:98(4):740-9.

[124] Wiener GJ, Richter JE, Copper JB, et al. The symptom index: a clinically important parameter of ambulatory $24 \mathrm{~h}$ esophageal $\mathrm{pH}$ monitoring. Am J Gastroenterol 1988;83(4):358-61.

[125] Breumelhof R, Smout AJ. The symptom sensitivity index: a valuable additional parameter in 24-hour esophageal pH recording. Am J Gastroenterol 1991;86:160-4.

[126] Weusten BL, Roelofs JM, Akkermans LM, et al. The symptom-association probability: an improved method for symptom analysis of 24-hour esophageal pH data. Gastroenterology 1994;107(6):1741-5.

[127] Herregods TVK, Pauwels A, Jafari J, et al. Determinants of reflux-induced chronic cough. Gut 2017;66:2057-62

[128] Herregods TVK, Pauwels A, Tack J, et al. Reflux-cough syndrome: assessment of temporal association between reflux episodes and cough bursts. Neurogastroenterol Motil 2017;29(12).

[129] Tsoukali E, Sifrim D. Investigation of extraesophageal gastroesophageal reflux disease. Ann Gastroenterol 2013;26:290-5.

[130] Ghisa M, Marinelli C, Savarino V, et al. Idiopathic pulmonary fibrosis and GERD: links and risks. Ther Clin Risk Manag 2019;15:1081-93.

[131] Tutuian R, Mainie I, Agrawal A, et al. Nonacid reflux in patients with chronic cough on acid-suppressive therapy. Chest 2006;130(2):386-91.

[132] Bolier EA, Kessing BF, Smout AJ, et al. Systematic review: questionnaires for assessment of gastroesophageal reflux disease. Dis Esophagus $2015 ; 28: 105-20$

[133] Savarino E, Zentilin P, Savarino V. NERD: an umbrella term including heterogeneous subpopulations. Nat Rev Gastroenterol Hepatol 2013;10:371-80.

[134] Savarino E, Bredenoord AJ, Fox M, et al. Advances in the physiological assessment and diagnosis of GERD. Nat Rev Gastroenterol Hepatol 2018;15:323.

[135] Martinucci I, de Bortoli N, Savarino E, et al. Esophageal baseline impedance levels in patients with pathophysiological characteristics of functional heartburn. Neurogastroenterol Motil 2014;26:546-55.

[136] Frazzoni M, Piccoli M, Conigliaro C, et al. Laparoscopic fundoplication for gastroesophageal reflux disease. World J Gastroenterol 2014:20:14272-9.

[137] Pauwels A, Boeckxstaens V, Andrews CN, et al. How to select patients for antireflux surgery? The ICARUS guidelines (international consensus regard- 
ing preoperative examinations and clinical characteristics assessment to select adult patients for antireflux surgery). Gut 2019;68:1928-41.

[138] Guarino MP, Cheng L, Ma J, et al. Increased TRPV1 gene expression in esophageal mucosa of patients with non-erosive and erosive reflux disease. Neurogastroenterol Motil 2010;22:746-51.

[139] Gyawali CP. Redeeming clinical value of esophageal pH impedance monitoring. Clin Gastroenterol Hepatol 2016;14:47-9.

[140] Eslick GD, Jones MP, Talley NJ. Non-cardiac chest pain: prevalence, risk factors, impact and consulting: a population-based study. Aliment Pharmacol Ther 2003;17:1115-24.

[141] Davies AM, Page Z, Rush EM, et al. Oesophageal stimulation lowers exertional anginal threshold. Lancet 1986;1(8436):1011-14.

[142] Prakash C, Clouse RE. Value of extended recording time with wireless pH monitoring in evaluating gastroesophageal reflux disease. Clin Gastroenterol Hepatol 2005;3:329-34.

[143] Dekel R, Pearson T, Wendel C, et al. Assessment of oesophageal motor function in patients with dyspepsia or chest pain - the clinical outcomes research initiative experience -. Aliment Pharmacol Ther 2003;18:1083-9.

[144] Dickman R, Mattek N, Holub J, et al. Prevalence of upper gastrointestinal tract findings in patients with noncardiac chest pain versus those with gastroesophageal reflux disease (GERD)-related symptoms: results from a national endoscopic database. Am J Gastroenterol 2007;102:1173-9.

[145] Dickman R, Emmons S, Cui H, et al. The effect of a therapeutic trial of high-dose rabeprazole on symptom response of patients with non-cardiac chest pain: a randomized, double-blind, placebo-controlled, crossover trial. Aliment Pharmacol Ther 2005;22:547-55.

[146] Bautista J, Fullerton H, Briseno M, et al. The effect of an empirical trial of high-dose lansoprazole on symptom response of patients with non-cardiac chest pain: a randomized, double-blind, placebo-controlled, crossover trial. Aliment Pharmacol Ther 2004;19:1123-30.

[147] Mauro A, Franchina M, Elvevi A, et al. Yield of prolonged wireless pH monitoring in achalasia patients successfully treated with pneumatic dilation. United Eur Gastroenterol J 2017;5:789-95.

[148] Katz PO, Gerson LB, Vela MF. Guidelines for the diagnosis and management of gastroesophageal reflux disease. Am J Gastroenterol 2013;108:308-28.

[149] Blondeau K, Dupont LJ, Mertens V, et al. Improved diagnosis of gastro-oesophageal reflux in patients with unexplained chronic cough. Aliment Pharmacol Ther 2007;25:723-32.

[150] Pouderoux P, Ergun GA, Lin S, et al. Esophageal bolus transit imaged by ultrafast computerized tomography. Gastroenterology 1996;110: 1422-1428.

[151] Holloway RH, Hongo M, Berger $K$, et al. Gastric distention: a mechanism for postprandial gastroesophageal reflux. Gastroenterology 1985;89: 779-784.
[152] Scheffer RC, Akkermans LM, Bais JE, et al. Elicitation of transient lower oesophageal sphincter relaxations in response to gastric distension and meal ingestion. Neurogastroenterol Motil 2002;14:647-55.

[153] Dent J, Dodds WJ, Friedman RH, et al. Mechanism of gastroesophageal reflux in recumbent asymptomatic human subjects. J Clin Invest 1980;65:256-67.

[154] Wyman JB, Dent J, Heddle R, et al. Control of belching by the lower oesophageal sphincter. Gut 1990;31:639-46.

[155] Klauser AG, Schindlbeck NE, Muller-Lissner SA. Symptoms in gastro-oesophageal reflux disease. Lancet 1990;335:205-8.

[156] Talley NJ, Stanghellini V, Heading RC, et al. Functional gastroduodenal disorders. Gut 1999;45(suppl 2):II37-42.

[157] Bredenoord AJ, Weusten BL, Sifrim D, et al. Aerophagia, gastric, and supragastric belching: a study using intraluminal electrical impedance monitoring. Gut 2004:53:1561-5.

[158] Hemmink GJ, Bredenoord AJ, Weusten BL, et al. Supragastric belching in patients with reflux symptoms. Am J Gastroenterol 2009;104(8):1992-7.

[159] Koukias N, Woodland P, Yazaki E, et al. Supragastric belching: prevalence and association with gastroesophageal reflux disease and esophageal hypomotility. J Neurogastroenterol Motil 2015;21:398-403.

[160] Glasinovic E, Wynter E, Arguero J, et al. Treatment of supragastric belching with cognitive behavioral therapy improves quality of life and reduces acid gastroesophageal reflux. Am J Gastroenterol 2018;113:539-47.

[161] Sawada A, Anastasi N, Green A, et al. Management of supragastric belching with cognitive behavioural therapy: factors determining success and follow-up outcomes at 6-12 months post-therapy. Aliment Pharmacol Ther 2019;50:530-7.

[162] Sifrim D, Zerbib F. Diagnosis and management of patients with reflux symptoms refractory to proton pump inhibitors. Gut 2012;61:1340-54.

[163] Ribolsi M, Cicala M, Zentilin P, et al. Prevalence and clinical characteristics of refractoriness to optimal proton pump inhibitor therapy in non-erosive reflux disease. Aliment Pharmacol Ther 2018:48:1074-81.

[164] Savarino V, Marabotto E, Zentilin P, et al. Proton pump inhibitors: use and misuse in the clinical setting. Expert Rev Clin Pharmacol 2018;11:1123-34.

[165] Savarino V, Dulbecco P, Savarino E. Are proton pump inhibitors really so dangerous? Dig Liver Dis 2016;48:851-9.

[166] Savarino V, Marabotto E, Zentilin P, et al. Pathophysiology, diagnosis, and pharmacological treatment of gastro-esophageal reflux disease. Expert Rev Clin Pharmacol 2020;17:1-13.

[167] Vaezi MF, Richter JE. Role of acid and duodenogastroesophageal reflux in gastroesophageal reflux disease. Gastroenterology 1996;111:1192-9.

[168] Alexander JA, Ravi K, Geno DM. Comparison of mucosal impedance measurements throughout the esophagus and mucosal eosinophil counts in endoscopic biopsy specimens in eosinophilic esophagitis. Gastrointest Endosc 2019;89:693-700. 